\title{
How Changes in Expectations of Earnings Affect the Associations of Earnings Overstatements and Audit Effort with Audit Risk and Market Price
}

\author{
Evelyn R. Patterson* \\ Kelley School of Business \\ Indiana University \\ evpatter@iupui.edu \\ Phone: (317)278-7843 \\ Fax: (317) 274-3312 \\ J. Reed Smith \\ Kelley School of Business \\ Indiana University \\ jrsmith2@iupui.edu \\ Phone: (317)274-0867 \\ Fax: (317) 274-3312 \\ Samuel L. Tiras \\ Kelley School of Business \\ Indiana University \\ stiras@iu.edu \\ Phone: (317)274-3420 \\ Fax: (317) 274-3312
}

April 2020

We are grateful to the Kelley School of Business, Indiana University for providing summer research support.

*Corresponding author 


\title{
How Changes in Expectations of Earnings Affect the Associations of Earnings Overstatements and Audit Effort with Audit Risk and Market Price
}

\begin{abstract}
In this study, we consider how changing expectations of earnings affect a dishonest manager's strategy to overstate earnings and an auditor's strategy to exert effort in a two-period setting. We model the manager type as either honest or dishonest, which allows us to differentiate audit risk from audit effort. Researchers typically assume audit effort and audit risk are negatively associated, which we find for changes in our period 2 payoff parameters, but we find the association can be positive, specifically with changes in our period 1 game parameters. Further, by dichotomizing, we show that the directional change in market price does not necessarily follow the directional change in audit effort as the prior literature suggests, because market price also adjusts for expected bias through changes in the intercept. A key finding is that when period 1 expected earnings increase, the probability that the manager is dishonest decreases, which allows the auditor to reduce audit effort. This finding suggests that observations of earnings that just meet or beat an earnings target and suspected of being managed may not be indicative of an audit failure, but indicative of an efficient allocation of effort. Finally, our multiperiod setting demonstrates that the effects from a change in the manager's or auditor's incentives in period 1 may reverse in period 2. Studies typically examine the contemporaneous effects of these changes on market price and/or audit risk, but fail to identify the cross-temporal effects we document in our study.
\end{abstract}




\section{How Changes in Expectations of Earnings Affect the Associations of Earnings Overstatements and Audit Effort with Audit Risk and Market Price}

\section{Introduction}

When economic conditions change from one period to the next, the auditor must assess the risk of overstatement by anticipating both the manager's incentives for fraudulent reporting and the effects of the changing economic conditions. If the auditor myopically focuses on a single period, the manager would be more likely to successfully implement a reporting strategy that fraudulently overstates earnings. In general, the risk of fraud is believed to be tied to economic conditions as Wilkinson (2015) documents:

A survey conducted by Deloitte \& Touche in late 2008 showed that $63 \%$ of the firm's clients expected an increase in fraud related to the global financial crisis experienced in that year. This would seem to indicate that, at a minimum, people expect more fraud to occur during an economic downturn.

The passage above highlights the auditor's awareness that bad economic conditions provide managers greater incentive to commit fraud and overstate earnings. These incentives follow from the pressure on managers to maintain stock value, which is typically tied to the manager's compensation package. These incentives may be further exacerbated by firms that respond to bad economic conditions by implementing a cost-cutting strategy that weakens systems of internal controls over financial reporting. Wilkinson (2015) also points out below that the seeming increase in fraud during an economic downturn may be related more to the effort to detect fraud than to an actual increase in the commission of fraud.

However, it may be that fraud is simply more likely to be discovered during times of economic stress. When business is good, people don't tend to question anomalies as thoroughly and small frauds might even be dismissed in an effort to maintain focus on growth, not problems.

Thus, when economic conditions are good, growth in reported earnings is not only plausible, but expected. The challenge facing the auditor is to determine whether an observed growth in 
reported earnings is a natural consequence of good economic conditions or whether those conditions simply enable managers to overstate earnings.

While deteriorating (improving) economic conditions lead to a decline (increase) in expected earnings in a given reporting period, it is important to consider the effect of changing economic conditions on both the manager's and auditor's strategies associated with previous and future periods. ${ }^{1}$ Currently, there is no theoretical guidance that considers how changes in expected earnings affect the interrelation between the manager's reporting strategy and the auditor's detection strategy, nor their combined impact on firm valuation. The purpose of this paper, therefore, is to consider how the changes in expected earnings affect these strategies, and how the interrelation of audit effort and earnings overstatements affect audit risk and market price.

We examine a two-period model of strategic auditing in which a manager issues a report on privately observed earnings, the auditor chooses audit effort after observing the report, and the market prices the firm's shares based on the expected value of earnings, conditional on the audited report. We assume that only the manager knows his type - either honest or dishonest, where the honest manager reports earnings truthfully and the dishonest manager overreports earnings. Because we restrict our attention to two manager types, our model allows us to assess how changes in payoff parameters affect audit risk and market price.

This paper is closely related to Patterson, Smith, and Tiras (PST) (2019b) who consider how changes in expected audit quality and expected reporting bias affect the earnings response coefficient (ERC). To obtain a continuous ERC, they model the manager's type as a continuum. ${ }^{2}$ However, the

\footnotetext{
${ }^{1}$ Auditing Standard (AS) 2401: Consideration of Fraud in a Financial Statement Audit. AS 2401.A.2 lists "Financial stability or profitability is threatened by economic, industry, or entity operating conditions," as a fraud risk factor.

${ }^{2}$ With only two manager types, the market response to reported earnings is necessarily a linear combination between the market responses for the honest and dishonest manager, where this linear combination yields an earnings response coefficient (ERC) of one. In PST (2019b), the continuous manager-type assumption allows the authors to focus on a continuous ERC, but does not allow them to evaluate the market price because the ERC and intercept change simultaneously. Despite these modeling differences, our one-period model yields comparative statics that are consistent with those in PST (2019b), thus providing assurance about the reasonableness of our modeling assumptions.
} 
continuum of manager types does not allow PST(2019b) to assess how changes in the payoff parameters affect market price or the traditional audit risk measure that includes an updated assessment of the manager's type as either dishonest or honest. In contrast to our model, audit risk in PST(2019b) depends only on audit effort. ${ }^{3}$

While the focus of our study is on the effects of the modeling parameters in our two-period model, we begin with a one-period setting that illustrates the basic elements of our model and provides a bridge between the modeling assumptions of this paper and those found in PST (2019b) and PST(2019a). The one-period model yields a manager's reporting strategy that is linear in true earnings and a market price that is linear in the earnings report. It also allows us to validate our model constructs relative to the extant literature and provides benchmark results for comparison with our two-period model.

When we extend the analysis to a two-period model, we address how changes in expected earnings in any given period, as well as changes in the payoff parameters, affect the manager's strategies, the auditor's strategies, audit risk, and market price for both the first and second period (the cross-period effects). For example, an increase in period 1 expected earnings not only results in an increase in the period 1 market price but also an increase in the period 2 market price. Moreover, our two-period model allows us to address how changes in period 2 expected earnings affect the period 1 strategies through the auditor's "look-head" strategy. In this case, the auditor chooses his period 1 strategy in anticipation of the payoffs and strategies he expects to encounter in period 2, with the objective of minimizing his total expected costs across both periods. As a result, if the auditor anticipates an increase in period 2 expected earnings, he increases period 1 audit effort and

\footnotetext{
${ }^{3}$ A continuum of manager payoff types in PST (2019b) implies that the probability of an honest manager has measure zero, and thus audit risk is equal to detection risk (audit risk is the updated probability of the dishonest type times the probability of non-detection). The true state of the world lies somewhere between the continuous-type world of PST (2019b) and the two-type world found in this paper.
} 
decreases period 2 audit effort. This combination of choices results in an increase in market price in both periods 1 and 2 .

In line with PST (2019a, 2019b), our study answers DeFond and Zhang's (2014) call for theoretical guidance for empirical audit research. Specifically, our findings provide new insights into how changing expectations of future earnings affect the auditor's effort within and across periods and the related implications of those effort changes on earnings overstatements, market price, and audit risk. For example, we find that when period 2 expected earnings increase, the auditor will exert more effort in period 1 and less in period 2, even though the dishonest manager is expected to increase the period 2 overstatement. Observations in the literature on meeting or beating earnings thresholds consistent with this result might seem to imply an audit failure in period 2. However, our analysis suggests otherwise, because audit effort in period 1 reduces the assessed likelihood that the manager is dishonest after period 1, which allows the auditor to efficiently reduce the period 2 audit effort since the auditor is optimally allocating audit effort across the two periods. We also show that the directional change in market price does not necessarily follow the directional change in audit effort as the prior literature suggests because the market price also adjusts for expected bias through changes in the intercept.

Our two-period analysis provides new insights about the limitations of a contemporaneous research design on assessing the implications of an exogenous shock to existing economic conditions. Our findings suggest that the short-term effects of an exogenous shock on market price and audit risk may be opposite of the long-term effects. Thus, the conclusions of those studies that test only the immediate market reactions or pool multiple periods subsequent to the shock may be miss-specified.

One significant contribution of the current study that is not found in previous strategic auditing research is the addition of a manager report and market pricing to a multi-period audit setting. Several studies examine issues related to managerial reporting. For example, Erard and 
Feinstein (1994) and Newman, Patterson and Smith (NPS) (2001) examine the auditor's response to an auditee in a setting similar to ours. ${ }^{4}$ However, neither study considers the stock market reaction to the report.

In contrast, Fischer and Verrecchia (2000) examine managerial reports and the stock market reaction to those reports in a one-period model, but do not consider the role of an external auditor. Caskey, Nagar, and Petacchi (2010) and PST (2019b) examine models that include managerial reports and the reaction of stock market participants in an environment with auditing, but these studies focus on a single-period analysis that cannot consider how changing economic conditions or changing payoffs affect the nature of the interaction across periods. We combine the essential elements of all of these papers in the current model.

One paper that does address multi-period fraud is PST (2019a), but without incorporating either a manager reporting strategy or a managerial payoff that depends on market price. Our approach to solving the model in this paper builds on the approach of PST (2019a), but we provide the auditor with a richer set of information that he can use in determining his audit strategy and, more importantly, we add an additional strategic player to the game: the market. Our results are consistent with PST (2019a), but our study expands on that analysis by demonstrating how the economic conditions and the players' payoffs affect their strategies, market price and audit risk, both within and across reporting periods.

The remainder of the paper is structured as follows. In section II, we examine a oneperiod benchmark model, which we expand to a multi-period model in section III. Section IV discusses empirical insights and implications of our results and section V concludes the paper.

\section{The one-period benchmark model}

\footnotetext{
${ }^{4}$ The NPS (2001) solution is similar to our one-period case, but limited in scope. It does not consider market prices and does not include a set of fully interactive auditor and manager payoffs.
} 
We begin with a one-period benchmark model that will subsequently allow us to evaluate the cross-period effects of changes in expected earnings in our two-period model. In order to assess the impact of expected earnings on reporting, audit risk, and the stock market reaction to reported earnings, we endow the manager with a reporting strategy.

We assume that the manager privately observes earnings $y$, where the dishonest manager has an incentive to choose a report $r[y]$ that overstates earnings $(r>y)$, while the honest manager always reports earnings truthfully $(r=y)$. The reporting function for the dishonest manager, $r[y]$ is invertible so that the inverse function, $y[r]=r^{-1}[y]$ is well-defined. ${ }^{5}$ We assume that earnings are (negative) exponentially distributed with density $\lambda \exp [-\lambda y]$ where the mean and variance of $y$ are $1 / \lambda$ and $1 / \lambda^{2}$, respectfully. ${ }^{6}$

\section{$<$ Place Figure 1 about here $>$}

The manager is dishonest with prior probability $\theta$ and honest with prior probability $1-\theta$. We assume earnings are non-negative and that the dishonest manager reports $r>y \geq 0$ where $r_{L B}$ is the lower bound on reported earnings such that $r \geq r_{L B}>0$ and $y\left[r_{L B}\right]=0.7$

After the manager reports earnings, the auditor observes the report $r$ and chooses detection

\footnotetext{
${ }^{5}$ We initially assume that the reporting function is linear, which is confirmed in equilibrium.

${ }^{6}$ The Gamma family of distributions are representative of distributions that are skewed to the right. In discussing the applicability of distributions such as the Gamma distribution, Casella and Berger $(1990,111)$ point out that firm "incomes are necessarily skewed to the right." Moreover, Wright (2011) provides additional evidence of earnings being skewed to the right. The exponential distribution is a good representative distribution (see Figure 1). Newman, Patterson and Smith (2001), who also assume that earnings are exponentially distributed, provide a numerical analysis that shows the overall strategic behavior of the auditor and manager is the same for several different members of the Gamma family. The use of the exponential distribution is necessary to derive a closed form solution for reported earnings.

${ }^{7}$ This assumption is consistent with the dishonest manager overreporting earnings. Consequently, if $r<r_{L B}$ the manager is revealed to be the honest type and audit risk is zero. Moreover, the dishonest manager does not mimic the honest manager's behavior because audit effort in this case is $x\left[r<r_{L B}\right]=0$, which would provide the dishonest manager with an incentive to issue a report $r \geq r_{L B}$. This feature of the solution is consistent with similar studies (see NPS 2001 and Erard and Feinstein 1994).
} 
effort $x[r]$, where the probability of detection is equal to $1-\exp [-x[r]]$. Because detection of overstatement is publicly observable, any restatement of the earnings report is known to the market.

Once the audit is complete and the auditor issues his report, the market prices the firm based on the conditional expectation of earnings given the report $r$ and the outcome of the audit. The market can infer earnings $y$ from $r$, only if the market knows the manager's type. If the manager is known to be dishonest, the market infers earnings are equal to $y[r]$, and if the manager is known to be honest, the market infers earnings as reported, $y=r$. Moreover, the market and the manager infer audit effort $x[r]$ based on the auditor's equilibrium strategy. ${ }^{8}$ Conditional on the report, the auditor evaluates the probability that the manager is dishonest as

$$
\operatorname{Pr}[D H \mid r]=\frac{\theta \exp [\lambda(r-y[r])] y^{\prime}[r]}{\theta \exp [\lambda(r-y[r])] y^{\prime}[r]+(1-\theta)}
$$

If the auditor does not detect fraud, the market infers the auditor's strategy and uses Bayes rule to update the probability that the manager is dishonest as

$$
\operatorname{Pr}[D H \mid r, N D]=\frac{\theta \exp [\lambda(r-y[r])] y^{\prime}[r] \exp [-x[r]]}{\theta \exp [\lambda(r-y[r])] y^{\prime}[r] \exp [-x[r]]+(1-\theta)}
$$

Thus, the market price ( $\mathrm{mp}$ ) of the firm, given no detection, is

$$
m p=E[y \mid r, N D]=r-\operatorname{Pr}[D H \mid r, N D](r-y[r]) .
$$

\section{Expected payoffs}

If there is no detection, the dishonest manager's expected payoff is a function of firm value,

\footnotetext{
${ }^{8}$ Later we see that audit effort can simply be expressed as $x$ because we find that $x^{\prime}[r]=0$.
} 
such as stock options or market-based compensation; otherwise, the manager simply incurs a penalty. ${ }^{9}$ We therefore assume the benefit from non-detection is equal to $R m p=R(r-\operatorname{Pr}[D H \mid r, N D](r-y[r]))$ where $R$ scales the importance of market price in the manager's payoff. We also assume that if the auditor detects overstatement, then the manager is penalized $\frac{p}{2}(r-y)^{2}$ where $p$ is a penalty multiplier and, for simplicity, we assume that he foregoes the benefit of $R \mathrm{mp}$ when overstatement is detected. ${ }^{10}$

As a result, the manager's expected payoff is computed as

$$
M g r=R \operatorname{mp} \exp [-x[r]]-(1-\exp [-x[r]]) \frac{p}{2}(r-y)^{2}
$$

The auditor has two costs associated with an audit: a potential liability cost and the cost of audit effort. We assume that his liability cost is equal to $-L(r-y[r])$ and that the cost of audit effort is equal to $-k x$ where $L$ and $k$ are liability and effort cost multipliers, respectfully. The auditor also updates the probability of the dishonest type, given $r$, in assessing his expected liability cost from non-detection. Thus, the auditor's expected payoff is ${ }^{11}$

$$
A u d=-\operatorname{Pr}[D H \mid r] \exp [-x] L(r-y[r])-k x
$$

\section{Equilibrium analysis}

We begin by assuming that the auditor and market conjecture that $r=y+r_{L B}$ or

alternatively, $y[r]=r-r_{L B}$, which we show holds in equilibrium. ${ }^{12}$ Consequently, $y^{\prime}[r]=1$ and

\footnotetext{
${ }^{9}$ Because the honest manager is non-strategic, we hereafter refer to the dishonest manager as the manager unless stated otherwise.

${ }^{10} \mathrm{We}$ assume that if misstatement is detected, the manager does not capture the market price benefit of Ry. Our results would be qualitatively unchanged if we allowed the manager to receive this amount.

${ }^{11}$ Consistent with previous research, the auditor's fee is fixed at the point in time that he chooses audit effort because the auditor is not allowed to contract on a contingent fee basis.

${ }^{12} \mathrm{We}$ formulate the problem as a system of ordinary differential equations with boundary conditions. But, as our conjecture holds in equilibrium, the differential equations in $r$ are trivial because $y^{\prime}[r]=1$ and $x^{\prime}[r]=0$. As a result,
} 
$y^{\prime \prime}[r]=0$. As a result,

$\frac{d \operatorname{Pr}[D H \mid r]}{d r}=\frac{(1-\theta) \theta \exp [\lambda(r-y[r])]\left(y^{\prime \prime}[r]-y^{\prime}[r] \lambda\left\{y^{\prime}[r]-1\right\}\right)}{\left(\exp [\lambda(r-y[r])] y^{\prime}[r] \theta+(1-\theta)\right)^{2}}=0$, where the update based

on the report is imbedded in $\exp [\lambda(r-y[r])] y^{\prime}[r]$.

The probability of the dishonest type relative to the honest type is captured by the Likelihood Ratio (LR), which is equal to $\frac{\exp [-\lambda y[r]] y^{\prime}[r]}{\exp [-\lambda r]}=\exp [\lambda(r-y[r])] y^{\prime}[r]$. This is greater than one because $\exp [\lambda(r-y[r])]>1$. Thus, for a given amount of realized earnings a higher report indicates a higher likelihood that the manager is the dishonest type.

To determine the players' equilibrium strategies, we first determine their first-order conditions.

Auditor:

The auditor's first order condition is

$\frac{d A u d}{d x}=\operatorname{Pr}[D H \mid r] \exp [-x] L(r-y[r])-k=0$

which implies that

$x=\log \left[\frac{L}{k} \operatorname{Pr}[D H \mid r](r-y[r])\right]$.

As a result, we find that the auditor does not depend on a specific report $r$ in determining his choice

of audit effort, because, as we see below, $\frac{d x}{d r}=0$.

the ERC is 1. That is, for a given set of fixed payoffs and for each dollar increase in the report $r$, the (unknown) inferred true earnings $y$ increases by a dollar. However, if either of the player's payoffs change, the report and the market price for a given $y$ also change. 
$\frac{d x}{d r}=\frac{1}{\operatorname{Pr}(D H \mid r)(r-y[r])}\left(\operatorname{Pr}(D H \mid r)\left(1-y^{\prime}[r]\right)+\frac{d \operatorname{Pr}(D H \mid r)}{d r}(r-y[r])\right)=0$

because $\left(1-y^{\prime}[r]\right)=0$ and $\frac{d \operatorname{Pr}(D H \mid r)}{d r}=0$. Without loss of generality, we hereafter use $x$ in the manager's first order condition rather than $x[r]$.

\section{Manager:}

The manager's first-order condition is

$\frac{d M g r}{d r}=R \exp [-x]-(1-\exp [-x]) p(r-y)=0$

because $\frac{d \operatorname{Pr}[D H \mid r]}{d r}=0$ and $\frac{d x}{d r}=0$ imply that $\frac{d \operatorname{Pr}(D H \mid r, N D)}{d r}=0$.

As a result, the manager overstates earnings for each observed earnings $y$ and each choice of audit effort $x$ by

$$
r-y=\frac{R}{p(\exp [x]-1)}=r_{L B}
$$

Expression (7) confirms our conjecture that the manager's reporting strategy is linear in equilibrium where $y^{\prime}[r]=1$.

Proposition 1: Equilibrium strategies for the auditor and manager, which are implicitly expressed in terms of $x$, equal the following.

$$
\begin{aligned}
\text { Manager: } r & =y+r_{L B} \text { where } r_{L B}=\frac{R}{p(\exp [x]-1)} \text { and } \\
\text { Auditor: } x & =\log \left[\frac{L}{k} \frac{\theta \exp \left[\lambda r_{L B}\right]}{\theta \exp \left[\lambda r_{L B}\right]+(1-\theta)} r_{L B}\right] \text { for all } r \geq r_{L B} . \\
x & =0 \text { for all } r<r_{L B} .
\end{aligned}
$$

(All proofs are in the Appendix.) 
Based on the equilibrium strategies, the updated probability of the dishonest type is $\frac{\theta \exp \left[\lambda r_{L B}\right]}{\theta \exp \left[\lambda r_{L B}\right]+(1-\theta)}$, which increases in $\exp \left[\lambda r_{L B}\right]$. The expression $\exp \left[\lambda r_{L B}\right]$ is the likelihood ratio of the dishonest type and only arises due to the inclusion of a manager reporting strategy; otherwise, the probability of the dishonest type is simply $\theta$. As either $r_{L B}$ or $\lambda$ increases, there is a higher likelihood that the manager is dishonest. Moreover, because $E[y]=1 / \lambda$ is expected earnings, $\lambda r_{L B}$ represents the proportion of expected earnings associated with overstatement. Thus, as $\lambda$ increases expected earnings decrease and a higher percentage of expected earnings is associated with a given overstatement $r_{L B}$.

\section{Comparative analysis}

In this section, we consider how the players' strategy choices, market price and audit risk change with changes in the game parameters: $L, k, R, p$, and $\lambda$. Audit risk $(A R)$ is equal to the probability of undetected overstatement $A R=\operatorname{Pr}[D H \mid r] \exp [-x]$ and market price is defined in expression (1). ${ }^{13}$ The analysis regarding effort $x$ must be done implicitly because the auditor's equilibrium effort choice is an implicit function of $x$ due to the inclusion of the earnings report in the probability assessment of the dishonest type.

Proposition 2 characterizes how changes in the model parameters affect the equilibrium values.

Proposition 2. Table 1 presents the changes in players' strategies as well as audit risk and market price that result from changes in each of the parameters $L, k, R, p$, and $\lambda$.

\footnotetext{
${ }^{13}$ The components of our benchmark model combine elements of both NPS (2001) and PST (2019b). The underlying distribution of earnings and the dichotomous manager types (honest and dishonest) are characteristics of NPS (2001), while the market reaction to reported earnings and the auditor's fraud detection technology are consistent with assumptions found in PST (2019b). Collectively, these assumptions are necessary to solve the two-period model in the next section and to evaluate a more traditional measure of audit risk as well as the role of changing earnings expectations on market pricing.
} 
TABLE 1

Comparative Analysis of the One-Period Model

\begin{tabular}{|c|c|c|c|c|}
\hline & \multicolumn{4}{|c|}{ Effect on strategy } \\
\hline $\begin{array}{c}\text { Increase in } \\
\text { parameter }\end{array}$ & $\begin{array}{c}\text { Audit effort } \\
\text { Overstatement } \\
r_{L B}\end{array}$ & $\begin{array}{c}\text { Audit risk } \\
\operatorname{Pr}[D H \mid r] \exp [-x]\end{array}$ & $\begin{array}{c}\text { Market Price } \\
r-\operatorname{Pr}[D H \mid r, N D] r_{L B}\end{array}$ \\
\hline \hline$k$ & + & - & - & + \\
\hline$k$ & - & + & + & - \\
\hline$R$ & + & + & - & + \\
\hline$p$ & - & - & + & + \\
\hline $1 / \lambda$ & - & + & - & + \\
\hline
\end{tabular}

Table 1 indicates how audit effort, earnings overstatement, audit risk and market price (firm value) are affected by changes in any one of our game parameters. The basic comparative analysis of how changes in the payoff parameters affect earnings overstatement and audit effort found in Table 1 of Proposition 2, is consistent with other papers such as PST (2019b). However, we add a new dimension to these results by also considering how changes in the payoff parameters $L, k, R$, and $p$ affect market price and audit risk. Moreover, beyond what has been examined in the prior literature, we include the effects of a change in expected earnings $1 / \lambda$ on overstatement, audit effort, market price, and audit risk.

With an increase in expected earnings $1 / \lambda$, the likelihood ratio of the dishonest type relative to the honest type decreases so that $\operatorname{Pr}[D H \mid r]$ decreases, which in turn decreases audit effort $x$ and induces the manager to increase overstatement $r_{L B}$. Thus, despite a reduction in audit effort $x$ and an increase in overstatement $r_{L B}$, both of which have a positive impact on audit risk, the dominant effect is the decrease in the likelihood ratio, thereby decreasing audit risk. 
Consistent with PST (2019b), audit risk and audit effort are inversely related for a change in each of the payoff parameters. This confirms that audit effort in a one period setting is a good proxy for assessing audit quality ( 1 - audit risk) in the context of a change in payoff parameter. However, this inverse relationship does not hold for a change in expected earnings. In this case, audit risk and audit effort both decrease in expected earnings. In PST (2019b) a change in expected earnings has no effect on expected bias or expected audit effort.

When we consider the effects of model parameters on market price, changes in $\operatorname{Pr}[D H \mid r, N D]$ correlate to changes in audit quality so that one might presume that audit quality and market price change in the same directions. However, this does not hold for changes in the manager's payoff parameters, due to the direct effect that these parameters have on overstatement $r_{L B}$. For example, an increase in the benefit parameter $R$ increases audit effort $x$ and decreases audit risk, but also increases overstatement $r_{L B}$, where the increase in $r_{L B}$ drives down market price despite the decrease in audit risk. Consequently, audit quality and market price are not necessarily positively associated as is typically presumed in the literature.

\section{The two-period model}

In the two-period setting all of the payoff parameters and strategies are the same as in the oneperiod model except that we use subscripts 1 and 2 to indicate whether it pertains to period 1 or period 2, respectively. Following the time-line of events depicted below, the two-period game begins by the manager observing period 1 earnings $y_{1}$. The dishonest manager issues an earnings report $r_{1}>y_{1}\left[r_{1}\right]$ where $y_{1}\left[r_{L B, 1}\right]=0$ and the honest manager issues an earnings report $r_{1}=y_{1}$. As before,

we assume that $y_{1}^{\prime}\left[r_{1}\right]=1$ and then show that this is supported in equilibrium. The auditor observes the report and chooses audit effort $x_{1}$ based on his updated assessment 
$\operatorname{Pr}\left[D H \mid r_{1}\right]=\frac{\theta \exp \left[\lambda_{1}\left(r_{1}-y_{1}\left[r_{1}\right]\right)\right]}{\theta \exp \left[\lambda_{1}\left(r_{1}-y_{1}\left[r_{1}\right]\right)\right]+(1-\theta)}$ that the manager is the dishonest (DH) type. The

auditor observes the outcome of his evidence choice and if no fraud is detected, designated as $N D_{1}$,

(which is publicly observed), the game continues to period 2.

Time-line of Events: Two-period Model

\begin{tabular}{|c|c|c|c|}
\hline | -------- & ---1 & | ------ & \\
\hline \multirow{2}{*}{$\begin{array}{l}\text { The manager privately } \\
\text { observes earnings } y_{1} \text { and } \\
\text { then chooses report } r_{1} \text {. } \\
\text { The auditor chooses } \\
\text { effort } x_{1} \text { after updating } \\
\text { the probability the } \\
\text { manager is the dishonest } \\
\text { type based on the report } \\
r_{1} .\end{array}$} & $\begin{array}{l}\text { The market updates the } \\
\text { firm's market price } \\
\text { based on the report and } \\
\text { whether the auditor } \\
\text { detects an } \\
\text { overstatement. If } \\
\text { overstatement is }\end{array}$ & \multirow{3}{*}{$\begin{array}{l}\text { The manager privately } \\
\text { observes earnings } y_{2} \text { and } \\
\text { then chooses report } r_{2} \text {. } \\
\text { The auditor chooses effort } \\
x_{2} \text { after updating the } \\
\text { probability the manager is } \\
\text { the dishonest type, based } \\
\text { on reports } r_{1} \text { and } r_{2} \text {, along } \\
\text { with the fact that no } \\
\text { overstatement was } \\
\text { detected in period } 1 .\end{array}$} & \multirow[t]{3}{*}{$\begin{array}{l}\text { The market updates the } \\
\text { firm's market price } \\
\text { based on both reports } \\
\text { and whether the auditor } \\
\text { detects an } \\
\text { overstatement. }\end{array}$} \\
\hline & $\begin{array}{l}\text { detected } m p_{1}=y_{1} \text { and } \\
\text { the game ends; } \\
\text { otherwise, we continue } \\
\text { to period } 2 .\end{array}$ & & \\
\hline & & & \\
\hline
\end{tabular}

The manager then observes period 2 earnings and issues an earnings report; $r_{2}=y_{2}$ for the honest type manager and $r_{2}>y_{2}\left[r_{2}\right]$ for the dishonest type manager with $y_{2}\left[r_{L B, 2}\right]=0$ and $y_{2}^{\prime}\left[r_{2}\right]=1$. The auditor again updates the probability of a dishonest type manager based on all the information he has to date that includes the period 1 earnings report, the period 1 evidence collected and the period 2 earnings report. The auditor then chooses period 2 audit effort $x_{2}$ based on his updated assessment of the dishonest type (i.e., the auditor's fraud risk assessment) which is $\operatorname{Pr}\left[D H \mid r_{1}, r_{2}, N D_{1}\right]=\frac{\theta \exp \left[-x_{1}\right] \exp \left[\lambda_{1}\left(r_{1}-y_{1}\left[r_{1}\right]\right)+\lambda_{2}\left(r_{2}-y_{2}\left[r_{2}\right]\right)\right]}{\theta \exp \left[-x_{1}\right] \exp \left[\lambda_{1}\left(r_{1}-y_{1}\left[r_{1}\right]\right)+\lambda_{2}\left(r_{2}-y_{2}\left[r_{2}\right]\right)\right]+(1-\theta)}$. 
We also represent market price as two incremental assessments of firm value in periods 1 and 2, labeled $m p_{1}$ and $m p_{2}$, that are based on the earnings reports in periods 1 and 2 and the inferred auditor effort choice in each period. The market prices in periods 1 and 2 are $m p_{1}=r_{1}-\operatorname{Pr}\left[D H \mid r_{1}, N D_{1}\right]\left(r_{1}-y_{1}\left[r_{1}\right]\right)$ and $m p_{2}=r_{2}-\operatorname{Pr}\left[D H \mid r_{1}, r_{2}, N D_{1}, N D_{2}\right]\left(r_{2}-y_{2}\left[r_{2}\right]\right)$.

We assume that $m p_{1}$ is conditioned on no detection in period 1 based on the inferred period 1 equilibrium audit effort because, if overstatement is detected, $m p_{1}$ is simply $y_{1}$. The price $m p_{1}$ is multiplied by the probability of non-detection in the manager's period 1 expected payoff function, which yields the expected firm value given "no detection." Similarly, $m p_{2}$ is conditioned on nondetection in both periods 1 and 2, where non-detection in period 1 is known at the start of period 2. Expected payoffs

Manager

First, we designate the manager's second period expected payoff, followed by his first period expected payoff. The manager's period 2 payoff is

$$
M g r_{2}=R_{1} m p_{1}+R_{2} m p_{2} \exp \left[-x_{2}\left[r_{2}\right]\right]-\left(1-\exp \left[-x_{2}\left[r_{2}\right]\right]\right) \frac{p_{2}}{2}\left(r_{2}-y_{2}\right)^{2}
$$

which is then incorporated into his first period payoff of

$$
M g r_{1}=M g r_{2} \exp \left[-x_{1}\left[r_{1}\right]\right]-\left(1-\exp \left[-x_{1}\left[r_{1}\right]\right]\right) \frac{p_{1}}{2}\left(r_{1}-y_{1}\right)^{2}
$$

Expression (8) assumes that the manager has consumed or otherwise "cashed-in" the market value from period 1 so that at the start of period 2 the period 1 benefit cannot be reclaimed.

\section{Auditor}

Similarly, define the auditor's second period payoff as

$$
A u d_{2}=-\operatorname{Pr}\left[D H \mid r_{1}, r_{2}, N D_{1}\right] \exp \left[-x_{2}\right] L_{2}\left(r_{2}-y_{2}\left[r_{2}\right]\right)-k_{2} x_{2} .
$$


$A u d_{2}$ is then included in the auditor's period 1 expected payoff, because he has the ability to anticipate his period 2 choice. ${ }^{14}$ Including $A u d_{2}$ in $A u d_{1}$ we obtain

$$
\begin{aligned}
& A u d_{1}=- \operatorname{Pr}\left[D H \mid r_{1}\right] \exp \left[-x_{1}\right] L_{1}\left(r_{1}-y_{1}\left[r_{1}\right]\right) \\
&+\left(\operatorname{Pr}\left[D H \mid r_{1}\right] \exp \left[-x_{1}\right]+\left(1-\operatorname{Pr}\left[D H \mid r_{1}\right]\right)\right) A u d_{2}-k_{1} x_{1}
\end{aligned}
$$

where $\left(\operatorname{Pr}\left[D H \mid r_{1}\right] \exp \left[-x_{1}\right]+\left(1-\operatorname{Pr}\left[D H \mid r_{1}\right]\right)\right)$ is the probability that the game continues to

\section{period 2.}

Equilibrium analysis

First consider the auditor's choice of audit effort in each period. Working backwards from the second period to the first period, we take derivatives with respect to $x_{1}$ and $x_{2}$.

$$
\begin{gathered}
\frac{d A u d_{2}}{x_{2}}=\operatorname{Pr}\left[D H \mid r_{1}, r_{2}, N D_{1}\right] \exp \left[-x_{2}\right] L_{2}\left(r_{2}-y_{2}\left[r_{2}\right]\right)-k_{2}=0, \text { which implies that } \\
\exp \left[-x_{2}\right]=\frac{k_{2}}{\operatorname{Pr}\left[D H \mid r_{1}, r_{2}, N D_{1}\right] L_{2}\left(r_{2}-y_{2}\left[r_{2}\right]\right)} .
\end{gathered}
$$

Based on the above condition we see that $x_{2}$ depends on $x_{1}$ and, similar to the one-period setting, we have $x_{2}^{\prime}\left[r_{2}\right]=0$.

Substituting (12) back into $A u d_{2}$, we obtain $A u d_{2}=-k_{2}\left(1+x_{2}\right)$. Thus, the auditor's expected payoff at the beginning of period 1 , from (11) becomes

$$
\begin{aligned}
A u d_{1}=- & \operatorname{Pr}\left[D H \mid r_{1}\right] \exp \left[-x_{1}\right] L_{1}\left(r_{1}-y_{1}\left[r_{1}\right]\right) \\
& -\left(\operatorname{Pr}\left[D H \mid r_{1}\right] \exp \left[-x_{1}\right]+\left(1-\operatorname{Pr}\left[D H \mid r_{1}\right]\right)\right) k_{2}\left(1+x_{2}\right)-k_{1} x_{1} .
\end{aligned}
$$

\footnotetext{
${ }^{14}$ The manager can also use his knowledge of his period 2 reporting choice in choosing his period 1 report. But as we see in our equilibrium analysis, his choices for the two periods are separable except for his anticipation of the inferred audit effort choice for each period.
} 
For convenience, denote $\theta_{r_{1}}=\operatorname{Pr}\left[D H \mid r_{1}\right]$. Holding the manager's strategy fixed and using all the observable reporting information to update his assessment that the manager is the dishonest type, the auditor's period 1 condition for his choice of effort $x_{1}$ is implicitly defined as ${ }^{15}$

$$
\begin{aligned}
\frac{d A u d_{1}}{d x_{1}}=\theta_{r_{1}} \exp \left[-x_{1}\right]\left\{L_{1}\left(r_{1}-y_{1}\left[r_{1}\right]\right)+k_{2}\left(1+x_{2}\right)\right\}-\left(\theta_{r_{1}} \exp \left[-x_{1}\right]+\left(1-\theta_{r_{1}}\right)\right) k_{2} \frac{d x_{2}}{d x_{1}}-k_{1} \\
=\theta_{r_{1}} \exp \left[-x_{1}\right]\left\{L_{1}\left(r_{1}-y_{1}\left[r_{1}\right]\right)+k_{2}\left(1+x_{2}\right)\right\} \\
+k_{2}\left(1-\theta_{r_{1}}\right) \frac{\left(\left(1-\theta_{r_{1}}\right)+\theta_{r_{1}} \exp \left[-x_{1}\right]\right)}{\left(1-\theta_{r_{1}}\right)+\theta_{r_{1}} \exp \left[-x_{1}\right] \exp \left[\lambda_{2}\left(r_{2}-y_{2}\left[r_{2}\right]\right)\right]}-k_{1}=0 .
\end{aligned}
$$

Next, consider the manager's choice of overstatement. As before, we start at the end of the game and work backwards. We find, based on the auditor's first order conditions and our conjecture $y_{1}^{\prime}\left[r_{1}\right]=1, y_{2}^{\prime}\left[r_{2}\right]=1$, that $x_{1}^{\prime}\left[r_{1}\right]=0$ and $x_{2}^{\prime}\left[r_{2}\right]=0$. Thus we can just use $x_{1}$ and $x_{2}$ in the manager's expected payoffs. Taking the first derivative and similar to the one-period model, we have the following.

$$
\begin{aligned}
& \frac{M g r_{2}}{d r_{2}}=\exp \left[-x_{1}\right]\left(R_{2} \exp \left[-x_{2}\right]-(1-\exp [-x]) p_{2}\left(r_{2}-y_{2}\right)\right)=0 \text { where } \\
& r_{2}-y_{2}=\frac{R_{2}}{p_{2}\left(\exp \left[x_{2}\right]-1\right)}=r_{L B, 2} .
\end{aligned}
$$

Similarly, $\frac{M g r_{1}}{d r_{1}}=R_{1} \exp \left[-x_{1}\right]-\left(1-\exp \left[-x_{1}\right]\right) p_{1}\left(r_{1}-y_{1}\right)=0$ and

$$
r_{1}-y_{1}=\frac{R_{1}}{p_{1}\left(\exp \left[x_{1}\right]-1\right)}=r_{L B, 1}
$$

\footnotetext{
${ }^{15}$ We assume that $k_{2}<k_{1}$, as in PST (2019a), to ensure that an interior solution for $x_{1}$ exists for all possible values of $\theta$. This assumption is consistent with our intuition that the auditor gains auditing expertise for a particular client over time.
} 
Thus, in equilibrium, we find that $y_{1}^{\prime}\left[r_{1}\right]=1$ and $y_{2}^{\prime}\left[r_{2}\right]=1$, which confirms our conjecture.

Next, define

$$
\begin{aligned}
H\left[x_{1}\right]=\theta_{r_{1}} \exp \left[-x_{1}\right] & \left(L_{1} r_{L B, 1}+k_{2}\left(1+x_{2}\right)\right) \\
& +k_{2}\left(1-\theta_{r_{1}}\right) \frac{\left(\left(1-\theta_{r_{1}}\right)+\theta_{r_{1}} \exp \left[-x_{1}\right]\right)}{\left(1-\theta_{r_{1}}\right)+\theta_{r_{1}} \exp \left[-x_{1}\right] \exp \left[\lambda_{2} r_{L B, 2}\right]}-k_{1}=0
\end{aligned}
$$

as the auditor's equilibrium condition for his choice of $x_{1}$ in which the manager's equilibrium

choices have been imbedded. ${ }^{16}$ Thus, $\theta_{r_{1}}$ and $x_{2}$ include the manager's choice of $r_{L B, 1}$, and $x_{2}$ also

includes the manager's choice of $r_{L B, 2}$.

Proposition 3. In the two-period setting, the auditor and manager equilibrium strategies, which are implicitly defined in $x_{1}$ and $x_{2}$, are as follows.

\section{Manager:}

$r_{2}=y_{2}+r_{L B, 2}$ where $r_{L B, 2}=\frac{R_{2}}{p_{2}\left(\exp \left[x_{2}\right]-1\right)}$

$r_{1}=y_{1}+r_{L B, 1}$ where $r_{L B, 1}=\frac{R_{1}}{p_{1}\left(\exp \left[x_{1}\right]-1\right)}$

Auditor:

$x_{2}=\log \left[\frac{L_{2} r_{L B, 2}}{k_{2}} \frac{\theta_{r_{1}} \exp \left[-x_{1}\right] \exp \left[\lambda_{2} r_{L B, 2}\right]}{\left(1-\theta_{r_{1}}+\theta_{r_{1}} \exp \left[-x_{1}\right] \exp \left[\lambda_{2} r_{L B, 2}\right]\right)}\right]$

$x_{2}=0$ for all $r_{2}<r_{L B, 2}$.

\footnotetext{
${ }^{16}$ Note that because overstatement is constant for all observed $y_{1}$ and $y_{2}$, we need not take expectations in expressing the auditor's first order condition across the two periods. The likelihood ratios for the dishonest type relative to the honest type for the two periods are fully imbedded in $\exp \left[\lambda_{1} r_{L B, 1}\right]$ and $\exp \left[\lambda_{2} r_{L B, 2}\right]$.
} 
$x_{1}$ is the solution to $H\left[x_{1}\right]=0$

$x_{1}=0$ for all $r_{1}<r_{L B, 1}$.

Comparative Analysis

For the two-period setting, we break the comparative analysis into three parts. We first present Proposition 4 that characterizes the effect of parameter changes on the players' equilibrium strategies. We then present Proposition 5 that builds upon these strategic characterizations by showing the resulting effect of parameter changes on audit risk and market price. Finally, we provide a roadmap that links Proposition 4 and Proposition 5 by illustrating how the changes in the players' equilibrium strategies are associated with the changes in audit risk and market price across the two periods.

We consider both within-period and cross-period effects. The cross-period effects are: (1) those occurring in period 2 based on changes in the period 1 parameters and (2) those occurring in period 1 based on changes in period 2 parameters. We refer to these as "look-back" and "look-ahead" effects, respectively.

\section{Changes in earnings overstatement and audit effort based on changes in game parameters}

Proposition 4 details the results of the within and cross-period strategic choice interactions.

Proposition 4: Table 2 below presents the changes in players' strategies for changes in each payoff parameter as well as the change in expected earnings. 
TABLE 2

Comparative Analysis of Strategies, Payoffs, and Expected

Earnings across Two Periods

\begin{tabular}{|c|c|c|c|c|}
\hline & \multicolumn{4}{|c|}{ Effect on strategy } \\
\hline $\begin{array}{c}\text { Increase in } \\
\text { parameter }\end{array}$ & $\begin{array}{c}\text { Period 1 } \\
\text { audit effort } \\
x_{1}\end{array}$ & $\begin{array}{c}\text { Period 1 } \\
\text { overstatement } \\
r_{L B, 1}\end{array}$ & $\begin{array}{c}\text { Period 2 } \\
\text { audit effort } \\
x_{2}\end{array}$ & $\begin{array}{c}\text { Period 2 } \\
\text { overstatement } \\
r_{L B, 2}\end{array}$ \\
\hline$L_{1}$ & + & - & - & + \\
\hline$k_{1}$ & - & + & + & - \\
\hline$R_{1}$ & + & + & - & + \\
\hline$p_{1}$ & - & - & + & - \\
\hline $1 / \lambda_{1}$ & - & + & - & + \\
\hline$L_{2}$ & + & - & + & - \\
\hline$k_{2}$ & + & - & - & + \\
\hline$R_{2}$ & + & - & + & + \\
\hline$p_{2}$ & - & + & - & - \\
\hline $1 / \lambda_{2}$ & + & - & - & + \\
\hline
\end{tabular}

The effects of changes in the players' payoff parameters on the equilibrium strategies

As a check on the reasonableness of our model, we observe that the interactions within and across periods for changes in payoff parameters $\left(\left\{L_{i}, k_{i}, R_{i}, p_{i}\right\}, i \in\{1,2\}\right)$ are consistent with those found in PST (2019a), even though PST (2019a) did not consider the effects of expected earnings and reported earnings. Moreover, the comparative analyses within a single period, found in the shaded quadrants, are the same as the single-period results presented in Table 1 of Proposition $2 .{ }^{17}$

The non-shaded quadrants contain the cross-period effects. The first four rows of the nonshaded, upper right-hand quadrant provide the "look-back" cross-period effects and the lower lefthand quadrant provide the "look-ahead" cross-period effects. For example, when the auditor looks

\footnotetext{
${ }^{17}$ Note that while these results parallel those of the one-period model, their derivation not only includes the actions of both players within a single period but those anticipated in the other period as well. Consequently, the within period comparative analysis cannot be strictly interpreted as being equivalent to a one-period analysis because the amount of effort and overstatement are not the same even though the signs derived from the comparative analyses are the same.
} 
back to period 1 in which audit effort has increased in $L_{1}$, period 2 audit effort decreases because the second period probability assessment of the dishonest type decreases. Alternatively, in looking ahead to period 2, an anticipated increase in $L_{2}$ increases period 1 audit effort, because the auditor would like to avoid a more costly period 2 audit failure.

The effects of a change in expected earnings on the equilibrium strategies

Our multi-period reporting model allows us to assess the impact of economic conditions on the auditor and dishonest manager's multi-period strategies. The effects of a change in expected earnings within a given period (shown in the shaded portions of the table) are consistent with our findings in the single-period analysis in Table 1.

We provide the cross-period effects of changing economic conditions in the unshaded cells for $1 / \lambda_{1}$ and $1 / \lambda_{2}$. First, consider how an increase in expected earnings in period 1 impacts the players' strategies in period 2 (a "look-back" effect). An increase in $1 / \lambda_{1}$ reduces the auditor's assessment that management is dishonest in period 1 and in period 2. The auditor's and market's assessment in period 2 about the probability that the manager is dishonest carries forward all period 1 information that the auditor has obtained, including the likelihood of the dishonest type $\exp \left[r_{L B, 1} /\left(1 / \lambda_{1}\right)\right]$ and the probability of non-detection $\exp \left[-x_{1}\right]$. Together, these factors decrease the assessed likelihood that the manager is dishonest in period 2. This result that the likelihood $\exp \left[r_{L B, 2} /\left(1 / \lambda_{2}\right)\right]$ increases in $1 / \lambda_{1}$ is because $r_{L B, 2}$ increases in $1 / \lambda_{1}$ but $1 / \lambda_{2}$ is fixed in period 2. However, in equilibrium, this increase is overwhelmed by the decrease in the assessed likelihood from non-detection in period 1 . The increase in period 1 expected earnings has a dominant effect on 
the assesed probability of the dishonest type in period 2. Audit effort decreases while overstatement increases in both periods 1 and $2 .^{18}$

Next consider the impact of an anticipated increase in $1 / \lambda_{2}$ due to a positive forecast in economic conditions (a "look-ahead" effect). With an increase in $1 / \lambda_{2}$, the manager's type will more likely be assessed as honest in period 2, because the game continues to period 2 only if the auditor has not detected fraud in period 1. The auditor increases effort in period 1, because the period 1 audit effort is more cost effective than period 2 audit effort. In response, the dishonest manager is less aggressive in period 1 overstatement, waiting for a better opportunity to engage in overstatement in period 2.

\section{Changes in market price and audit risk based on changes in game parameters}

Next we consider the effects of changes in game parameters on audit risk and market price across the two periods. These results are found in Table 3 as part of Proposition 5. ${ }^{19}$

Proposition 5. Table 3 below presents the changes in audit risk and market price in periods 1 and 2 for changes in each payoff parameter and expected earnings.

\footnotetext{
${ }^{18}$ This is the only case where a period 1 parameter change does not result in a reversal of the change in audit effort choice between the two periods (see the top half of Table 2). Audit effort, $x_{1}$ and $x_{2}$ move in the opposite direction for each of the other parameter changes.

${ }^{19}$ Twenty-nine of the 40 results in this table are proven in the Appendix while the remaining 11 are established by numerical analysis. Because the equilibrium in the two-period model is necessarily characterized as a pair of equilibrium conditions rather than as closed-form solutions and because these conditions are restricted to ensure interior solutions, some derivatives cannot be signed analytically. These 11 results are the derivatives of $m p_{1}, A R_{1}$, and $m p_{2}$ with respect to $R_{1}, p_{1}$, and $1 / \lambda_{1}$ and the derivatives of $m p_{2}$ with respect to $R_{2}$ and $p_{2}$. All other results are derived analytically. The numerical analyses used to establish these 11 results are described in the Appendix.
} 
TABLE 3

Comparative Analysis of Market Pricing and Audit Risk across Two Periods

\begin{tabular}{|c|c|c|c|c|}
\hline & \multicolumn{4}{|c|}{ Effects on Market Price and Audit Risk } \\
\hline $\begin{array}{c}\text { Increase } \\
\text { in } \\
\text { parameter }\end{array}$ & $\begin{array}{c}\text { Period 1 } \\
\text { Audit Risk }\left(A R_{1}\right)\end{array}$ & $\begin{array}{c}\text { Period 1 } \\
\text { Market Price }\left(\mathrm{mp}_{1}\right)\end{array}$ & $\begin{array}{c}\text { Period 2 } \\
\text { Audit Risk }\left(A R_{2}\right)\end{array}$ & $\left.\begin{array}{c}\text { Period 2 } \\
\text { Market Price }\left(\mathrm{mp}_{2}\right)\end{array}\right) \exp \left[-x_{1}\right]$ \\
\hline \hline$L_{1}-\operatorname{Pr}\left[D H \mid r_{1}, N D_{1}\right] r_{L B, 1}$ & $\operatorname{Pr}\left[D H \mid r_{1}, r_{2}, N D_{1}\right] \exp \left[-x_{2}\right]$ & $r_{2}-\operatorname{Pr}\left[D H \mid r_{2}, r_{1}, N D_{1}, N D_{2}\right] r_{L B, 2}$ \\
\hline$k_{1}$ & - & + & - & + \\
\hline$R_{1}$ & + & - & + & - \\
\hline$p_{1}$ & - & - & - & + \\
\hline $1 / \lambda_{1}$ & + & + & + & + \\
\hline$L_{2}$ & - & + & - & + \\
\hline$k_{2}$ & - & + & + & - \\
\hline$R_{2}$ & - & + & - & - \\
\hline$p_{2}$ & + & + & + & + \\
\hline $1 / \lambda_{2}$ & - & - & - & + \\
\hline
\end{tabular}

The shaded quadrants of Table 3 include within period changes, which are consistent with those found in Table 1.

The "look-back" effects

Similar to Table 2, the upper right-hand quadrant of Table 3 illustrates the cross-period effects of changes in the period 1 game parameters on audit risk and market price in period 2 (the "lookback" effects). To illustrate, consider that an increase in the auditor's liability parameter $L_{1}$ increases $x_{1}$ while $r_{L B, 1}$ decreases. These two changes result in a decrease in period 1 audit risk and an increase in period 1 market price. Going on to period 2, the increase in period 1 audit effort produces a decrease in the updated probability of the dishonest type at the beginning of period 2. This decreases period 2 audit risk and increases period 2 market price despite the decrease in $x_{2}$. The opposite results obtain for an increase in the auditor cost parameter $k_{1}$. 
On the other hand, increases in the manager's period 1 payoff parameters produce surprising results. In period $2, R_{1}$, for example, does not have a direct payoff effect on the auditor's or manager's decisions. Its impact relates only to the effect that it has on audit effort in period 1. Since $R_{1}$ increases audit effort in period 1, the assessed likelihood that the manager is dishonest decreases at the beginning of period 2. This effect dominates the resulting decrease in $x_{2}$ and audit risk decreases as well. This implies that the market price in period 2 increases (a reversal of the period 1 effect on market price) because the updated probability of the dishonest type dominates. See Figure 2, for an example of how the manager's benefit parameter affects market price.

\section{$<$ Place Figure 2 about here $>$}

The other cross-period effects for changes in the period 1 payoff parameters work in much the same way. However, the increase in period 1 expected earnings $1 / \lambda_{1}$ reduces audit effort in both periods 1 and 2, but the carryforward of information that decreases the probability of the dishonest type in each period also decreases audit risk and increases market price in each period. Thus, favorable expectations in earlier periods aid in maintaining market price and audit quality in future periods, despite an increase in overstatement and a decrease in audit effort in each of those periods. The "look-ahead" effects

The bottom left-hand quadrant of Table 3 shows how audit risk and market price are affected by the auditor's "look ahead" strategy where the bottom right-hand (shaded) quadrant provides the within-period results that correspond to Table 1 . Similar to the top half of Table 3 , the findings presented in the bottom half of Table 3 are driven by the changes shown in Table 2. For example, an increase in the auditor's period 2 liability parameter $L_{2}$, increases audit effort in both periods 1 and 2 and an increase in period 1 audit effort decreases audit risk and increases market price in period 1. 
The "look-ahead" strategy for a change in $k_{2}$ produces somewhat different results than those corresponding with a change in $k_{1}$ found in the top half of Table 3.

As one might expect, the $k_{1}$ results are just the opposite of those for changes in $L_{1}$ across both periods. However, the results corresponding with an increase in $k_{2}$ produce an opposite effect to an increase in $L_{2}$ only in period 2. In period 1, an increase in $k_{2}$ decreases audit risk and increases market price. Knowing that the auditor adjusts his audit strategy based on anticipated costs, the market reflects these adjustments in the current year market price. An increase in $R_{2}$ and $p_{2}$ work much the same way as an increase in $R_{1}$ and $p_{1}$, only reversing the effects between periods 1 and 2. See Figure 2, for an example.

Finally, an increase in period 2 expected earnings $1 / \lambda_{2}$ decreases the within-period audit risk and increases the within-period market price, as discussed above regarding increases in period 1 expected earnings $1 / \lambda_{1}$. Moreover, because an increase in period 2 expected earnings $1 / \lambda_{2}$ increases period 1 audit effort $x_{1}$ and decreases period 1 overstatement $r_{L B, 1}$, as shown in Table 2 , audit risk decreases and market price increases in period 1 as well. Thus, the market embodies the auditor's "look-ahead" strategy in adjusting market price based on forecasted earnings. See Figure 3, for an example.

\section{$<$ Place Figure 3 about here $>$}

\section{The associations of audit effort and earnings overstatement with market price and audit risk}

Figure 4 consists of two panels; panel A presents the effects of changes in period 1 game parameters and panel B presents the effects of changes in period 2 game parameters. Proposition 4 (Table 2) provides the effects of changes in game parameters $\left(\left\{L_{i}, k_{i}, R_{i}, p_{i}, 1 / \lambda_{i}\right\}, i \in\{1,2\}\right)$ on the strategic choices of audit effort and earnings overstatement and are depicted on the left-hand side of 
each panel. Proposition 5 describes the effects of changes in payoffs and expected earnings on audit risk and market price. Figure 4 links the results of Propositions 4 and 5 to show how changes in payoffs and expected earnings affect the associations that involve earnings overstatements and audit effort with audit risk and market price. These associations are depicted on the right-hand side of each panel.

\section{$<$ Place Figure 4 about here $>$}

As an example, consider the first pair of associations provided on the right-hand side of panel A that we describe as " $\uparrow R_{1}, \downarrow p_{1}\left[\operatorname{Assoc}\left(E O_{1}, M P_{1}\right)<0,\left(E O_{2}, M P_{2}\right)>0\right]$. The interpretation of this notation is that increases in $R_{1}$ (or decreases in $p_{1}$ ) imply through the results of Propositions 4 and 5 that earnings overstatements are inversely associated with market price in period 1 whereas in period 2 earnings overstatements are directly associated with market price. These associations are determined as follows. Table 2 shows that increases in $R_{1}$ (decreases in $p_{1}$ ) imply an increase in earnings overstatement in periods 1 and 2 and Table 3 shows that increases in $R_{1}$ (decreases in $p_{1}$ ) imply that the market price in period 1 decreases while the market price in period 2 increases. Since period 1 overstatement increases in $R_{1}$ and the market price in period 1 decreases in $R_{1}$ we observe a negative association with respect to changes in $R_{1}$ and $p_{1}$. Similarly, since period 2 overstatement increases in $R_{1}$ and the market price in period 2 also increases, overstatement and market price in period 2 are positively association with respect to changes in $R_{1}$ and $p_{1}$.

The key takeaway from this section and Figure 4 is that the associations of audit effort and earnings overstatements with audit risk and market price vary, depending on how the game parameters change. The expected association between a change in earnings overstatement and a change in market price, for example, depends on whether the change is a result of an auditor payoff, a 
manager payoff, or a change in expected earnings. We show those associations that may be counterintuitive in bold. Our analysis provides insights into predicting these associations.

\section{Empirical insights and implications}

In focusing on the empirical insights and implications of our study, we begin by discussing how our key findings relate to those of PST (2019b). In their study, they focus on how market price responds to changes in the expected reporting bias and expected audit quality through the earnings response coefficient (ERC). They find that the directional change in ERCs follow the directional change in expected audit quality, but changes in ERCs may be positively or negatively associated with changes in expected reporting bias. $^{20}$

An important question that arises from PST's (2019b) findings that changes in the ERC follows the directional change in expected audit quality, rather than the directional change in expected reporting bias, is how market prices would reflect changes in expected reporting bias. PST (2019b) cannot address this issue because their model assumes all managers are dishonest to varying degrees, where the ERC varies with the managers' incentives for misstatement. As such, their model equates changes in expected audit quality (1-audit risk) with changes in audit effort. Therefore PST (2019b) cannot address how audit risk is affected by changes in either audit effort or the assessed risk that an earnings overstatement occurs.

In the current study, we dichotomize the manager type which leads to the ERC being constant and allows us to differentiate audit risk from audit effort. Thus, because we dichotomize, we show that the directional change in market price does not necessarily follow the directional change in audit

\footnotetext{
${ }^{20}$ As PST (2019b) explain, expected reporting bias decreases from increases in how costly it is for the manager to report biasedly or from decreases in the manager's benefit for reporting biasedly. As expected reporting bias decreases, the auditor would respond by reducing expected audit effort. Likewise, the manager would also reduce expected reporting bias when the auditor increases expected audit effort in response to an increase in the auditor's liability or a decrease in the auditor's cost of conducting an audit. In both situations, PST (2019b) demonstrate that the directional change in the ERC follows the directional change in audit quality, such that a decrease in expected reporting bias could be either positively or negatively associated with the ERC.
} 
effort, because market prices also adjust for the expected level of bias through changes in the intercept. $^{21}$ Together, the current study and PST (2019b) demonstrate that in order for empirical researchers to identify how market prices react and adjust to changes in reporting bias and audit effort, they must interpret changes in both the intercept and the slope (ERC) when regressing cumulative abnormal returns on unexpected earnings. Empirical accounting research, to date, focuses on how a particular issue affects only the slope without consideration of the intercept effects (for examples, see Kothari 2001; Dechow, Ge, and Schrand 2010; DeFond and Zhang 2014).

In contrast to the accounting literature, the finance literature considers both the slope and intercept effects when estimating the systematic risk in the capital asset pricing model (CAPM). Systematic risk is estimated by regressing the volatility of a particular stock on a market portfolio of stocks, where the slope coefficient on the market portfolio (beta) is the empirical estimate of the stock's systematic risk. The CAPM also includes an intercept (alpha) that captures firm specific stock volatility not derived from the volatility of the market. If beta is estimated without also estimating alpha, the estimate of beta would be biased. Similarly, if changes in ERCs are estimated without also estimating changes in the intercept, the estimate of the change in the ERC would be biased.

An important insight from our paper addresses the seemingly counterintuitive result found in the earnings management literature. Burgstahler and Dichev (1997) and Degeorge et al. (1999) find that the distribution of firms just short of an earnings threshold is unexpectedly low and the distribution of earnings that just meet or beat an earnings threshold is unexpectedly high, indicative that firms which just meet or beat earnings targets are manipulating. The motive for why a manager would manipulate earnings to meet an earnings target is clear, given the literature's findings of a

\footnotetext{
${ }^{21}$ While not addressed in PST (2019b), the intercept in their model is also affected by changes in expected reporting bias. Their study cannot address the overall effect that a change in expected reporting bias has on market price, because they allow both the intercept and ERC to change as expected reporting bias changes.
} 
severe contemporaneous negative market reaction for those firms that fall short of earnings targets (for example, Skinner and Sloan 2002). Thus for those firms that just meet or beat an earnings target, earnings are suspect such that practitioners and academic researchers would expect the auditor to exert greater effort in detecting earnings overstatements for these firms, for which the empirical literature has failed to find support.

In our study, we find that as period 2 expected earnings increase, the auditor efficiently increases effort in period 1 and decreases effort in period 2 (see panel B of Figure 4). This occurs even though the dishonest manager is expected to increase the period 2 overstatement, suggesting that the dishonest manager perceives there to be a level of overstatement that would not trigger the auditor to increase audit effort. The dishonest manager understands that as long as the reduced exposure from the lower likelihood that the manager is dishonest is greater than the increased exposure from the expected overstatement in reported earnings, the auditor will not increase audit effort. Thus, for those suspect firms, we find that a dishonest manager would limit the increase in overstatements to small increments (presumably just enough to meet or beat the target) and the auditor would not increase audit effort. The important insight from our study is that the empirical observations that suggest managers successfully overstate earnings to meet or beat an earnings target without triggering the auditor to increase audit effort is not necessarily a result of an audit failure, but follows from the auditor efficiently allocating audit effort.

An important implication of our multiperiod analysis relates to the empirical research that focuses on the manager's incentives to overstate earnings or the auditor's incentives to exert effort. These studies typically examine the contemporaneous implications of changes in these incentives on market price and/or audit risk (for a review, see DeFond and Zhang 2014). The evidence from these cross-sectional studies is generally in line with our one-period findings and documents the contemporaneous effects of an increased market price and reduced audit risk. However, the cross- 
sectional design of these studies fails to identify the cross-temporal effects from changes in the auditor's or manager's incentives documented in our two-period model.

In our two-period model, we show for period 1 that when auditor liability increases, audit effort increases and manager overstatement decreases (see panel A of Figure 4). But the increase in period 1 audit effort results in a lower likelihood of a dishonest manager in period 2. This lower likelihood results in both audit effort decreasing and manager overstatement increasing in period 2. Thus, the directional changes in audit effort and managerial overstatement from an increase in the auditor's liability in period 1 reverse in period 2.

Those empirical studies that examine the effects from changing regulations impacting the auditor's expected effort, such as SOX, typically examine either: (1) just the initial period following the enactment of the new regulation (for instance, DeFond, Hann, and Hu 2005); or, (2) several reporting periods following the regulations enactment, but examine the periods cross-sectionally in which each period is considered an independent observation (for instance, Bryan, Liu, Tiras, and Zhuang 2013). In the first case, a contemporaneous study could document the expected increase in audit effort and/or expected decrease in the overstatement of earnings, but this approach would not examine whether audit effort and/or the overstatement of earnings reverses in the next period. As such, the empirical conclusions would be incomplete in that only the short-term (period 1) effects of the changing regulation would be observed.

In the second case, because the short-term effects of the changing regulation are opposite from the long-term effects (period 2), a cross-sectional study that pools multiple periods could result in the effects being completely offset, mitigated, or opposite of the expected effects (if the long-term effects are larger than the short-term effects). The findings from our study suggest that empirical research that focuses on regulatory changes should examine the cross-temporal multiperiod effects of a change rather than the cross-sectional effects. 
While we focus on just three main insights and implications of our study on future empirical research, we expect that the new insights from our within-period and cross-period analyses will provide empirical researchers greater intuition in designing their empirical hypotheses. We expect these insights to shape future research on how changing economic conditions affect empirical studies related to earnings expectations, audit effort, earnings overstatements, market prices, and audit risk.

\section{Conclusion}

We analyze a setting in which the auditor designs an audit to detect a possible overstatement in reported earnings over multiple periods. Unique to the strategic auditing literature, we explicitly assess the effects of economic conditions on market price, audit effort, the extent of overstatement and audit risk. Anecdotal evidence as well as prior empirical studies suggest that economic conditions reflected in the forecast or expectation of earnings profoundly affect overstatements and the likelihood of auditor detection.

We find that under good economic conditions (higher expected earnings), the auditor reduces audit effort, and the manager increases the overstatement of earnings just enough so that the auditor is not motivated to increase audit effort. Good economic conditions reduces the auditor's updated probability that the manager is dishonest. Going forward into the next period, the higher expectations of period 1 spills over into period 2 and again the auditor reduces the amount of audit effort while the overstatement of earnings increases. Moreover, audit risk decreases with this decrease in audit effort. Alternatively, an anticipated or forecasted increase in expected earnings in a future period, increases audit effort and decreases the earnings overstatement in the current period, because this effectively decreases the cost of audit effort in the current period.

Our results also provide new insights into the way audit risk relates to audit effort. Audit researchers often use audit effort as a proxy for audit quality (1-audit risk), implicitly assuming that audit effort and audit risk are negatively associated. We find this negative association for any change 
in a period 2 payoff parameter (see Figure 4, Panel B). However, we find that audit risk and audit effort can be positively associated. Specifically, we find that for a change in any of the period 1 game parameters (see Figure 4, Panel A), period 2 audit risk and audit effort either both increase or both decrease.

The implications of our study on future empirical accounting research are three-fold. First, the extant empirical literature presumes that changes in expected reporting bias affects market prices through the ERC, but PST (2019b) find that changes in the ERC follows the directional change in expected audit effort, rather than the directional change in expected reporting bias. We find, however, that market prices adjust for the expected level of bias through changes in the intercept, suggesting that future empirical research that considers the relation between market prices and reporting bias analyze the relation through shifts in both the slope and intercept.

Second, the extant empirical literature that studies the effects of changing economic conditions on the auditor's incentives to exert effort or the manager's incentives to overstate earnings typically examine the contemporaneous implications of these changes on market price and/or audit risk. These studies examine either the period immediately following an exogenous shock to the existing economic conditions, or several reporting periods following the exogenous shock by considering each period as an independent observation. We find, however, that the short-term effects of an exogenous shock can be opposite from the long-term effects, suggesting that future empirical research on the effects of an exogenous shock to the existing economic conditions separately analyze the short-term and long-term implications of these changes on market price and/or audit risk.

Finally, much of the empirical financial literature utilizes earnings expectations as a benchmark for evaluating the quality of financial reporting. Examples include research on meeting or beating earnings expectations, unexpected earnings (i.e., reported earnings less expected earnings), expectations management, and more. Generally, these studies focus on one-period-ahead earnings 
forecasts. We find, however, that when improving economic conditions lead to expectations of higher long-term earnings (i.e., earnings growth), the auditor anticipates the reduced need to exert effort in the future period and assigns more resources to the current period (period 1). In this case, the dishonest manager overstates period 2 earnings but constrains the overstatement to small increments that would not trigger the auditor to increase period 2 audit effort. This finding may explain why the empirical financial literature regularly identifies firms with "suspect" earnings that just meet or beat an earnings benchmark. 
FIGURE 1

The Family of Curves Belonging to the Gamma Distribution

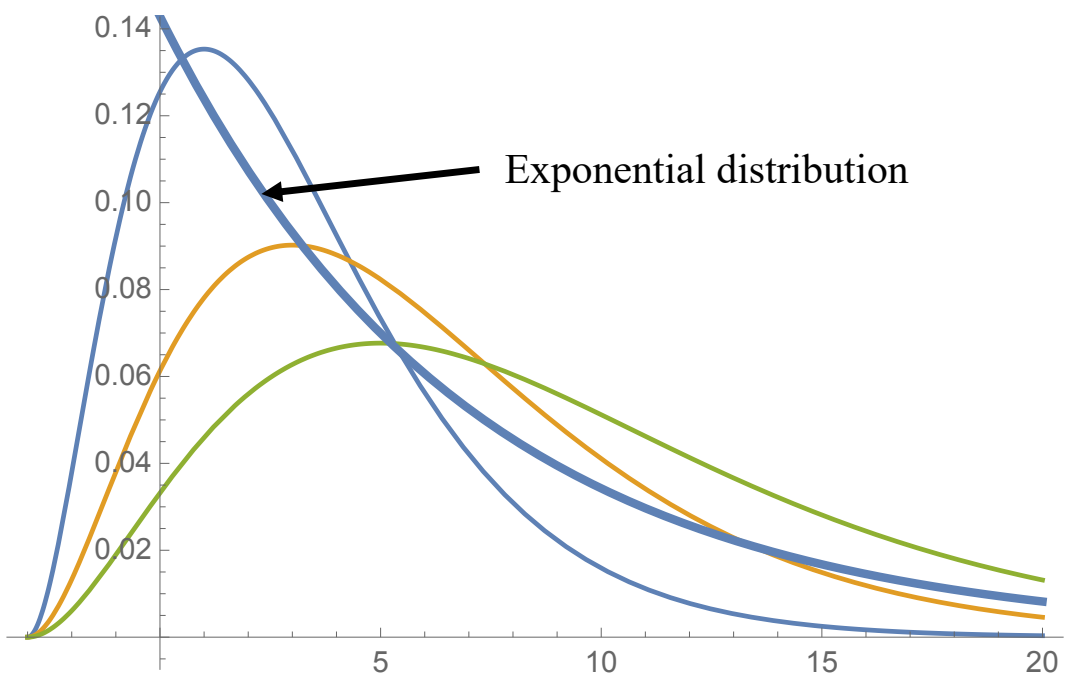


FIGURE 2

Comparison of Market Price in Periods 1 and 2 given

Increasing Managerial Benefits in each Period

Period 1 Market Price

$r_{1}-\operatorname{Pr}\left[D H \mid r_{1}, N D_{1}\right] r_{L B, 1}$

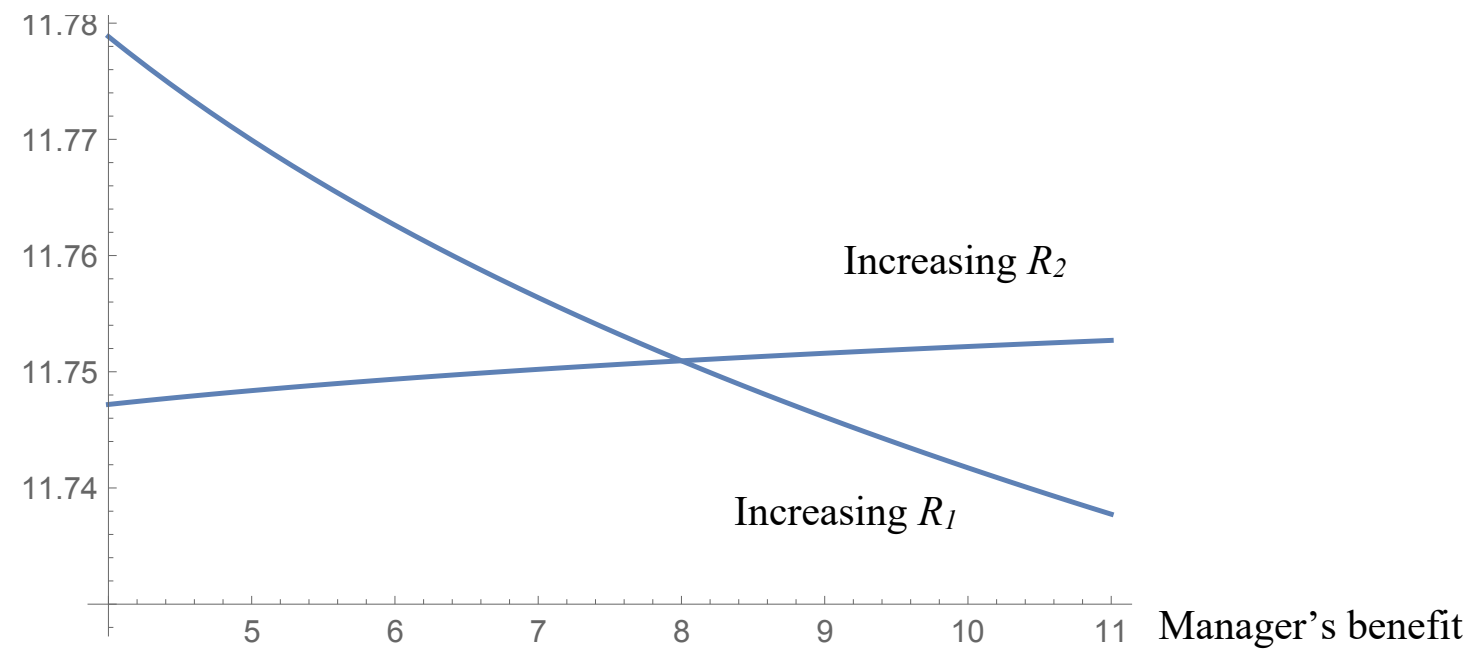

Panel A: Market price in period 1 (earnings report $=12)$

Period 2 Market Price

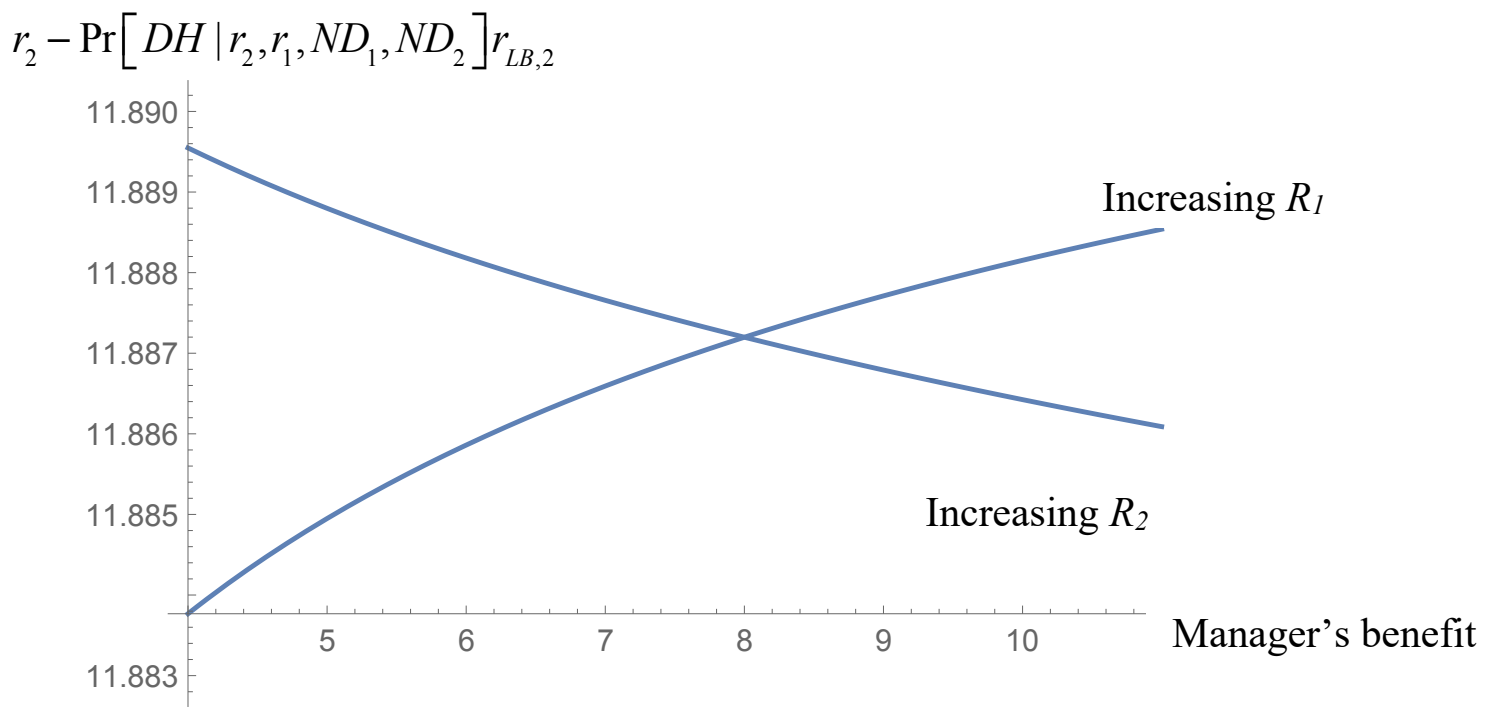

Panel B: Market price in period 2 (earnings report $=12$ ) 
FIGURE 3

Comparison of Market Price in Periods 1 and 2 given

Increasing Expected Earnings in each Period

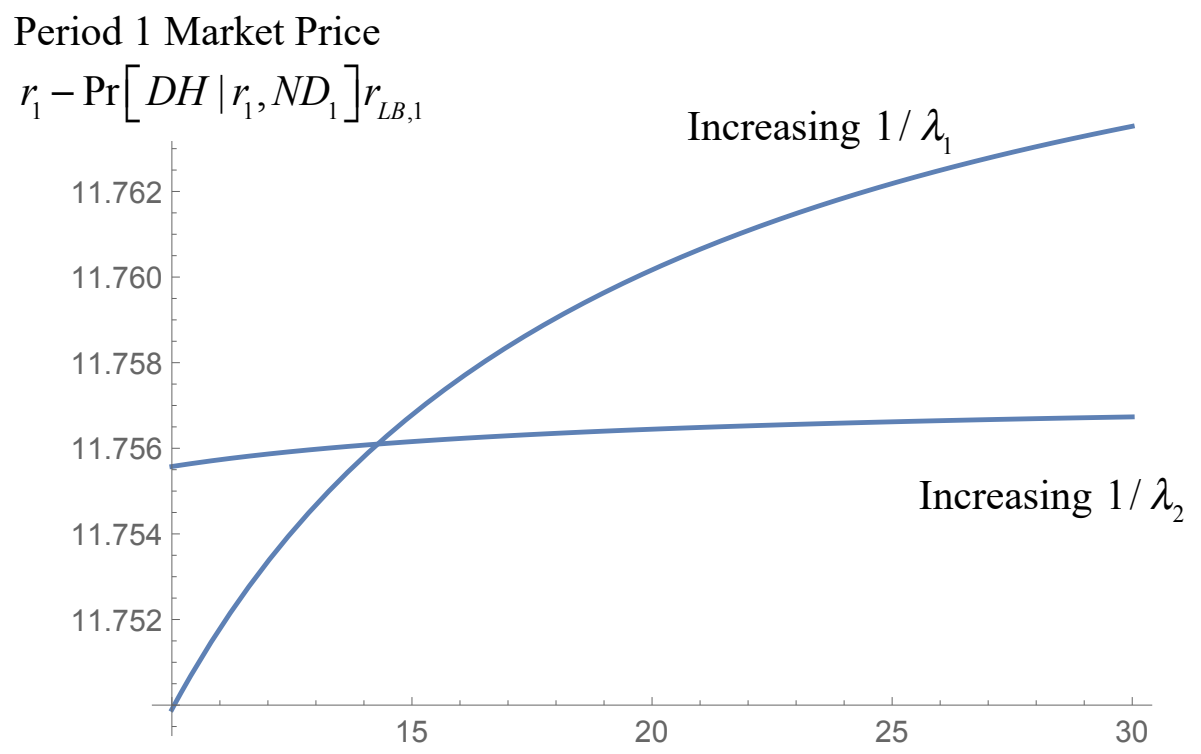

Panel A: Market price in period 1 (earnings report = 12)

Expected earnings

Period 2 Market Price

$r_{2}-\operatorname{Pr}\left[D H \mid r_{2}, r_{1}, N D_{1}, N D_{2}\right] r_{L B, 2}$

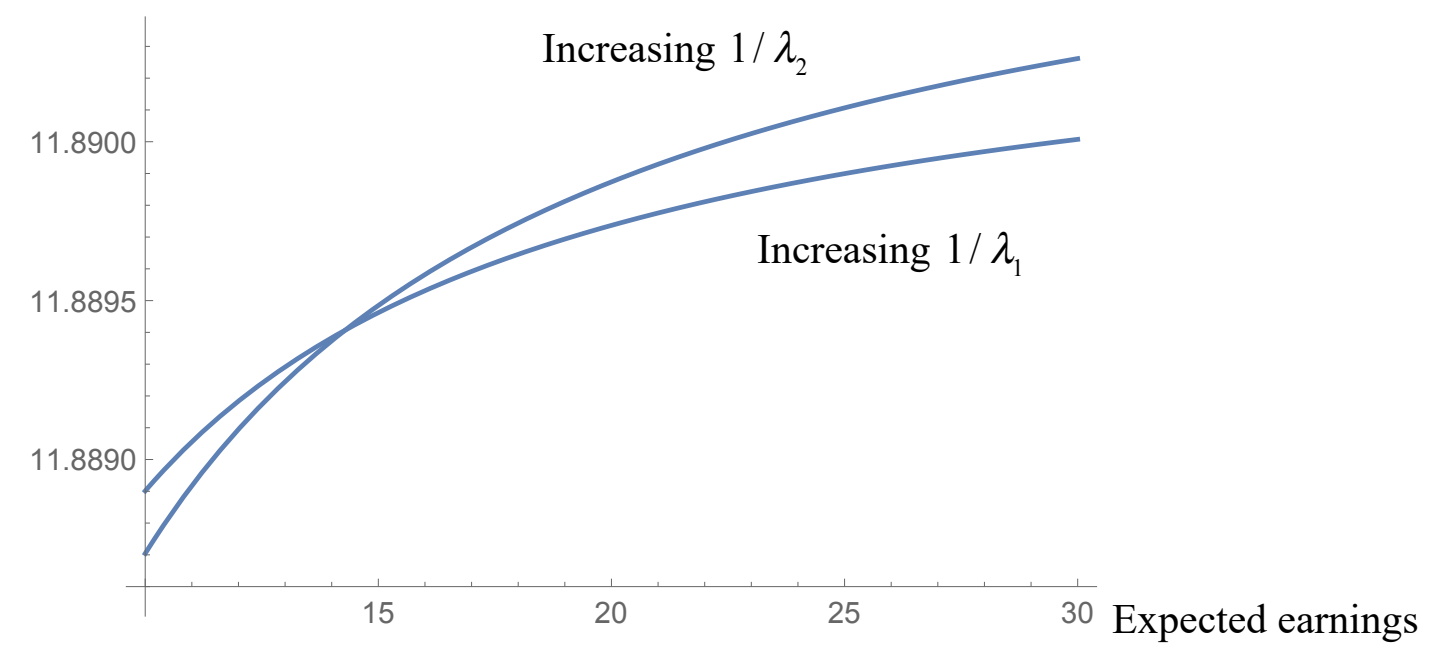

Panel B: Market price in period 2 (earnings report $=12$ ) 
FIGURE 4

The Cross-Period Effects of Changes in Game Parameters on Strategies, Audit Risk and Market Price

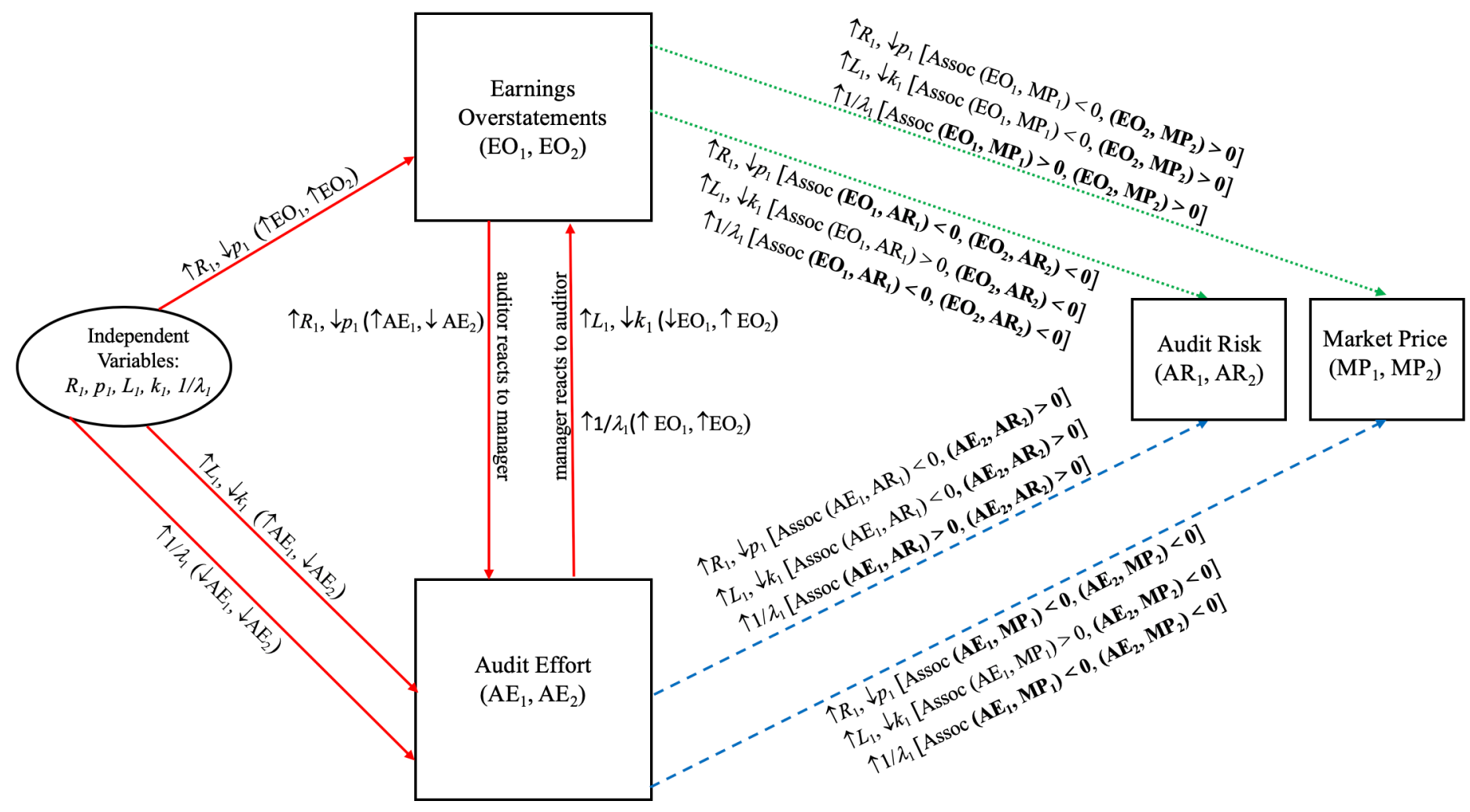

Panel A: Effects of changes in Period One Parameters

(bold indicates seemingly counterintuitive results) 


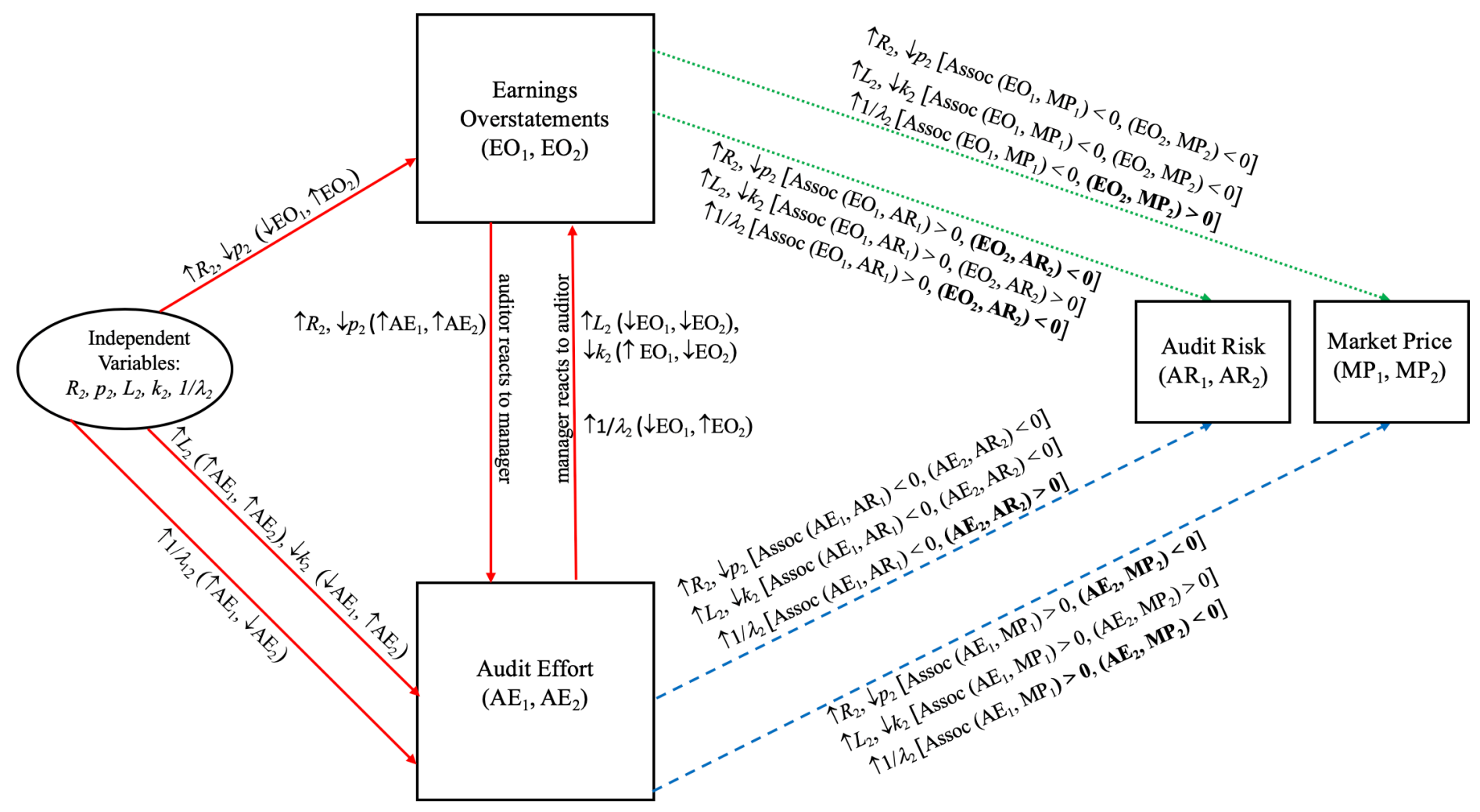

Panel B: Effects of Changes in Period Two Parameters

(bold indicates seemingly counterintuitive results)

indicates a causal relation,

$---\rightarrow$ indicates associations of audit effort with audit risk or market price that result from causal relation between independent variables $\left(R_{i}, p_{i}, L_{i}, k_{i}, 1 / \lambda_{i}, i=(1,2)\right)$ and audit effort; and,

indicates associations of earnings overstatements with audit risk or market price that result from causal relation between independent variables $\left(R_{i}, p_{i}, L_{i}, k_{i}, 1 / \lambda_{i}, i=(1,2)\right)$ and earnings overstatements. 


\section{Appendix}

\section{Proof of Proposition 1:}

The updated probability of the dishonest type given earnings report $r$ is

$\operatorname{Pr}[D H \mid r]=\frac{\theta \exp [\lambda(r-y[r])] y^{\prime}[r]}{\theta \exp [\lambda(r-y[r])] y^{\prime}[r]+(1-\theta)}$

If there is no detection of fraud based on the auditor's choice of audit effort, designated as ND, the market infers the probability of the dishonest type to be

$$
\begin{gathered}
\operatorname{Pr}[D H \mid r, N D]=\frac{\operatorname{Pr}[D H \mid r] \exp [-x[r]]}{\operatorname{Pr}[D H \mid r] \exp [-x[r]]+(1-\operatorname{Pr}[D H \mid r])} \\
=\frac{\theta \exp [\lambda(r-y[r])] y^{\prime}[r] \exp [-x[r]]}{\theta \exp [\lambda(r-y[r])] y^{\prime}[r] \exp [-x[r]]+(1-\theta)}
\end{gathered}
$$

As we note in section II of the paper,

$$
\frac{d \operatorname{Pr}[D H \mid r]}{d r}=\frac{(1-\theta) \theta \exp [\lambda(r-y[r])]\left(y^{\prime \prime}[r]-y^{\prime}[r] \lambda\left\{y^{\prime}[r]-1\right\}\right)}{\left(\exp [\lambda(r-y[r])] y^{\prime}[r] \theta+(1-\theta)\right)^{2}}=0
$$

because $y^{\prime}[r]=1$, based on our assumption.

Furthermore, as shown in expression (5)

$$
x=\log \left[\frac{L}{k} \operatorname{Pr}[D H \mid r](r-y[r])\right]
$$

and as s a result,

$$
\frac{d x}{d r}=\frac{1}{\operatorname{Pr}(D H \mid r)(r-y[r])}\left(\operatorname{Pr}(D H \mid r)\left(1-y^{\prime}[r]\right)+\frac{d \operatorname{Pr}(D H \mid r)}{d r}(r-y[r])\right)=0
$$

because $\left(1-y^{\prime}(r)\right)=0$ and $\frac{d \operatorname{Pr}(D H \mid r)}{d r}=0$ so that $x^{\prime}[r]=0$. 
Based on the above, the first order condition for the manager is

$\frac{d M g r}{d r}=R \exp [-x]-(1-\exp [-x[r]]) p(r-y)=0$

Thus, $r=y+r_{L B}$ where $r_{L B}=\frac{R}{p(\exp [x]-1)}$, which is consistent with our assumption of $y^{\prime}[r]=1$.

And again, from expression (5) we know that

$$
x=\log \left[\frac{L}{k} \operatorname{Pr}[D H \mid r](r-y[r])\right] .
$$

Thus,

$$
x=\log \left[\frac{L}{k} \frac{\theta \exp \left[\lambda r_{L B}\right]}{\theta \exp \left[\lambda r_{L B}\right]+(1-\theta)} r_{L B}\right], \text { which defines } x \text { implicitly. }
$$

Corollary 1: Without regard to a change in payoff parameter, market price increases and audit risk decreases in audit effort $x$.

\section{Proof:}

Market price $m p=r-\operatorname{Pr}[D H \mid r, N D] r_{L B}$ and audit risk $A R=\operatorname{Pr}[D H \mid r] \exp [-x]$.

Now $m p=r-\frac{\theta \exp \left[\lambda r_{L B}\right] \exp [-x]}{\theta \exp \left[\lambda r_{L B}\right] \exp [-x]+(1-\theta)} r_{L B}$ so that

$$
\begin{aligned}
& \frac{d m p}{d x}=\frac{\partial m p}{\partial x}+\frac{\partial m p}{\partial r_{L B}} \frac{d r_{L B}}{d x}>0 \text { where } \\
& \frac{\partial m p}{\partial x}=\frac{\exp \left[x+\lambda r_{L B}\right] r_{L B}(1-\theta) \theta}{\left(\exp [x](1-\theta)+\exp \left[\lambda r_{L B}\right] \theta\right)^{2}}>0 \text { and } \\
& \frac{\partial m p}{\partial r_{L B}} \frac{d r_{L B}}{d x}=\frac{\theta \exp \left[x+\lambda r_{L B}\right] r_{L B}\left(\exp \left[\lambda r_{L B}\right] \theta+\exp [x](1-\theta)\left(1+\lambda r_{L B}\right)\right)}{(-1+\exp [x])\left(\exp [x](1-\theta)+\exp \left[\lambda r_{L B}\right] \theta\right)^{2}}>0 \\
& \frac{d A R}{d x}=\frac{d\left(\frac{\theta \exp \left[\lambda r_{L B}\right]}{\theta \exp \left[\lambda r_{L B}\right]+(1-\theta)} \exp [-x]\right)}{d x}=\frac{\partial A R}{\partial x}+\frac{\partial A R}{\partial r_{L B}} \frac{d r_{L B}}{d x}<0 \text { where }
\end{aligned}
$$


$\frac{\partial A R}{\partial x}=-\frac{\exp \left[-x+\lambda r_{L B}\right] \theta}{1+\left(-1+\exp \left[\lambda r_{L B}\right]\right) \theta}<0$ and $\frac{\partial A R}{\partial r_{L B}} \frac{d r_{L B}}{d x}=-\frac{\exp \left[\lambda r_{L B}\right] \lambda r_{L B}(1-\theta) \theta}{(-1+\exp [x])\left(1+\left(-1+\exp \left[\lambda r_{L B}\right]\right) \theta\right)^{2}}<0$

which has the opposite sign of $\frac{d m p}{d x}$.

\section{Proof of Proposition 2:}

To facilitate the analysis we define

$$
x_{\log }=\log \left[\frac{L}{k} \frac{\theta \exp \left[\lambda r_{L B}[x]\right]}{\theta \exp \left[\lambda r_{L B}[x]\right]+(1-\theta)} r_{L B}[x]\right]
$$

in order to distinguish between the general expression for $x$ and those $x$ 's imbedded in the Log

expression. (Recall that $x$ is defined implicitly as $-x+x_{\log }=0$ so that we must use implicit

differentiation.)

Thus $\frac{d x}{d g}=\frac{\partial x_{\log } / \partial g+\left(\partial x_{\log } / \partial r_{L B}\right)\left(\partial r_{L B} / \partial g\right)}{-\partial\left(-x+x_{\log }\right) / \partial x-\left(\partial\left(-x+x_{\log }\right) / \partial r_{L B}\right)\left(d r_{L B} / d x\right)}$ where $g$ is one of our payoff

parameters. Furthermore, because $r_{L B}{ }^{\prime}[x]=\frac{d r_{L B}}{d x}<0$,

$\frac{-\partial\left(-x+x_{\text {log }}\right)}{\partial x}-\frac{-\partial\left(-x+x_{\text {log }}\right)}{\partial r_{L B}} \frac{d r_{L B}}{d x}=-\frac{r_{L B}{ }^{\prime}[x]}{r_{L B}[x]}+\frac{1-\theta+\exp \left[\lambda r_{L B}[x]\right] \theta-\lambda(1-\theta) r_{L B}{ }^{\prime}[x]}{1-\theta+\exp \left[\lambda r_{L B}[x]\right] \theta}>0$.

Thus, the sign of $\frac{d x}{d g}$ depends solely on the sign of $\frac{\partial x_{\log }}{\partial g}+\frac{\partial x_{\log }}{\partial r_{L B}} \frac{\partial r_{L B}}{d g}$.

And $\frac{d r_{L B}}{d g}=\frac{\partial r_{L B}}{\partial g}+\frac{\partial r_{L B}}{\partial x} \frac{d x}{d g}=\frac{\partial r_{L B}}{\partial g}+r_{L B} \frac{-\exp [x]}{-1+\exp [x]} \frac{d x}{d g}$

Proof of $\frac{d x}{d L}>0, \frac{d x}{d k}<0, \frac{d r_{L B}}{d L}<0, \frac{d r_{L B}}{d k}>0$

$$
\frac{\partial x_{\log }}{\partial L}+\frac{\partial x_{\log }}{\partial r_{L B}} \frac{\partial r_{L B}}{d L}=\frac{1}{L}+0>0 \text { and } \frac{\partial x_{\log }}{\partial k}+\frac{\partial x_{\log }}{\partial r_{L B}} \frac{\partial r_{L B}}{d k}=-\frac{1}{k}+0<0
$$


$\frac{d r_{L B}}{d L}=\frac{\partial r_{L B}}{\partial L}+\frac{\partial r_{L B}}{\partial x} \frac{d x}{d L}=0+r_{L B} \frac{-\exp [x]}{-1+\exp [x]} \frac{1}{L}<0$ and similarly, $\frac{d r_{L B}}{d k}>0$.

Proof of $\frac{d x}{d R}>0, \frac{d x}{d p}<0, \frac{d r_{L B}}{d R}>0, \frac{d r_{L B}}{d p}<0$

$\frac{\partial x_{\log }}{\partial R}+\frac{\partial x_{\log }}{\partial r_{L B}} \frac{\partial r_{L B}}{d R}=0+r_{L B} \frac{(1-\theta)\left(1+\lambda r_{L B}\right)+\theta \exp \left[\lambda r_{L B}\right]}{r_{L B}\left((1-\theta)+\theta \exp \left[\lambda r_{L B}\right]\right)} \frac{1}{p(-1+\exp [x])}>0$

$\frac{d x}{d p}=\frac{\partial x_{\log }}{\partial p}+\frac{\partial x_{\log }}{\partial r_{L B}} \frac{\partial r_{L B}}{d p}=0+r_{L B} \frac{(1-\theta)\left(1+\lambda r_{L B}\right)+\theta \exp \left[\lambda r_{L B}\right]}{r l b\left((1-\theta)+\theta \exp \left[\lambda r_{L B}\right]\right)} \frac{-R}{p^{2}(-1+\exp [x])}<0$

$\frac{d r_{L B}}{d R}=\frac{\partial r_{L B}}{\partial R}+\frac{\partial r_{L B}}{\partial x} \frac{d x}{d R}=\frac{1}{p(-1+\exp [x])}+r l b \frac{-\exp [x]}{-1+\exp [x]} \frac{d x}{d R}$

$=\frac{(-1+\exp [x])\left(1+\left(-1+\exp \left[\lambda r_{L B}\right]\right) \theta\right)}{(-1+\exp [x])(-1+2 \exp [x]) p\left(1+\left(-1+\exp \left[\lambda r_{L B}\right]\right) \theta\right)+\exp [x] R(1-\theta) \lambda}>0$

Similarly, $\frac{d r_{L B}}{d p}<0$

Proof of $\frac{d x}{d \lambda}>0, \frac{d r_{L B}}{d \lambda}<0$

$\frac{\partial x_{\log }}{\partial \lambda}+\frac{\partial x_{\log }}{\partial r_{L B}} \frac{\partial r_{L B}}{d \lambda}=\frac{r_{L B}(1-\theta)}{1-\theta+\theta \exp \left[\lambda r_{L B}\right]}+0>0$

And $\frac{d r_{L B}}{d \lambda}=\frac{\partial r_{L B}}{\partial \lambda}+\frac{\partial r_{L B}}{\partial x} \frac{d x}{d \lambda}=0+r l b \frac{-\exp [x]}{-1+\exp [x]} \frac{d x}{d \lambda}<0$

Proof of $\frac{d A R}{d L}<0, \frac{d m p}{d L}>0, \frac{d A R}{d k}>0$, and $\frac{d m p}{d k}<0$

$\frac{d A R}{d L}=\frac{d A R}{d x} \frac{d x}{d L}<0$ and $\frac{d m p}{d L}=\frac{d m p}{d x} \frac{d x}{d L}>0$ based on Corollary 1 and $\frac{d x}{d L}>0$, as shown above.

Similarly, $\frac{d A R}{d k}>0$, and $\frac{d m p}{d k}<0$. 


$$
\begin{aligned}
& \text { Proof of } \frac{d A R}{d R}<0, \frac{d m p}{d R}<0, \frac{d A R}{d p}>0 \text {, and } \frac{d m p}{d p}>0 \\
& \frac{d A R}{d R}=\frac{\partial A R}{\partial R}+\frac{d A R}{d x} \frac{d x}{d R}=\frac{-\theta \exp \left[-x+\lambda r_{L B}\right]}{\left(1+\lambda r_{L B}(1-\theta)+\theta\left(-1+\exp \left[\lambda r_{L B}\right]\right)\right)} \frac{d x}{d R}<0 \text { and similarly, } \frac{d A R}{d p}>0 \\
& \frac{d m p}{d R}=\frac{d m p}{d x} \frac{d x}{d R}+\frac{\partial m p}{\partial r_{L B}} \frac{d r_{L B}}{d R} \\
& =-\frac{\exp \left[2 \lambda r_{L B}\right] r_{L B}}{\left(\exp [x](-1+\theta)-\exp \left[\lambda r_{L B}\right] \theta\right)^{2}\left(1+\lambda r_{L B}(1-\theta)+\theta\left(-1+\exp \left[\lambda r_{L B}\right]\right)\right)} \frac{d x}{d R}<0
\end{aligned}
$$

In a similar fashion, $\frac{d m p}{d p}>0$.

Proof of $\frac{d A R}{d \lambda}>0$ and $\frac{d m p}{d \lambda}<0$

$$
\frac{d A R}{d \lambda}=\frac{\partial A R}{\partial \lambda}+\frac{d A R}{d x} \frac{d x}{d \lambda}=\frac{\exp \left[\lambda r_{L B}\right] \theta}{(-1+\exp [x])\left(1+\left(-1+\exp \left[\lambda r_{L B}\right]\right) \theta\right)} \frac{d x}{d \lambda}>0
$$

and $\frac{d m p}{d \lambda}=\frac{\partial m p}{\partial \lambda}+\frac{d m p}{d x} \frac{d x}{d \lambda}=\frac{-2 \exp \left[x+\lambda r_{L B}\right] r_{L B} \theta^{2}}{\left(\exp [x](1-\theta)+\exp \left[\lambda r_{L B}\right] \theta\right)^{2}} \frac{d x}{d \lambda}<0$

\section{Proof of Proposition 3.}

Expressions (14) and (15) yield the manager's equilibrium strategies. We use expression (12)

$$
\begin{aligned}
& \exp \left[-x_{2}\right]=\frac{k_{2}}{\operatorname{Pr}\left[D H \mid r_{1}, r_{2}, N D_{1}\right] L_{2}\left(r_{2}-y_{2}\left[r_{2}\right]\right)} \text { to solve for } \\
& x_{2}=\log \left[\frac{L_{2} r_{L B, 2}}{k_{2}} \frac{\theta_{r_{1}} \exp \left[-x_{1}\right] \exp \left[\lambda_{2} r_{L B, 2}\right]}{\left(1-\theta_{r_{1}}+\theta_{r_{1}} \exp \left[-x_{1}\right] \exp \left[\lambda_{2} r_{L B, 2}\right]\right)}\right] \text { and expression (16) } \\
& H\left[x_{1}\right]=\theta_{r_{1}} \exp \left[-x_{1}\right]\left(L_{1} r_{L B, 1}+k_{2}\left(1+x_{2}\right)\right)
\end{aligned}
$$




$$
+k_{2}\left(1-\theta_{r_{1}}\right) \frac{\left(\left(1-\theta_{r_{1}}\right)+\theta_{r_{1}} \exp \left[-x_{1}\right]\right)}{\left(1-\theta_{r_{1}}\right)+\theta_{r_{1}} \exp \left[-x_{1}\right] \exp \left[\lambda_{2} r_{L B, 2}\right]}-k_{1}=0
$$

defines the auditor's equilibirum period 1 effort $x_{1}$ after substituting for the manager's equilibrium strategies.

\section{Proof of Proposition 4.}

We begin by proving that $H^{\prime}\left[x_{1}\right]<0$ where

$$
\begin{aligned}
H\left[x_{1}\right]=\theta_{r_{1}} \exp \left[-x_{1}\right]\left(L_{1} r_{L B, 1}+k_{2}\left(1+x_{2}\right)\right) \\
+k_{2}\left(1-\theta_{r_{1}}\right) \frac{\left(\left(1-\theta_{r_{1}}\right)+\theta_{r_{1}} \exp \left[-x_{1}\right]\right)}{\left(1-\theta_{r_{1}}\right)+\theta_{r_{1}} \exp \left[-x_{1}\right] \exp \left[\lambda_{2} r_{L B, 2}\right]}-k_{1}
\end{aligned}
$$

such that all equilibrium strategies have been included.

Moreover, for ease of notation, let $x_{2 L o g}=\log \left[\frac{L_{2} r_{L B, 2}}{k_{2}} \frac{\theta_{r_{1}} \exp \left[-x_{1}\right] \exp \left[\lambda_{2} r_{L B, 2}\right]}{\left(1-\theta_{r_{1}}+\theta_{r_{1}} \exp \left[-x_{1}\right] \exp \left[\lambda_{2} r_{L B, 2}\right]\right)}\right]$.

Then we express $\frac{\partial x_{2 \log } / \partial x_{1}}{-\partial\left(-x_{2}+x_{2 \log }\right) / \partial x_{2}}=\frac{\partial x_{2 \log } / \partial x_{1}}{-\left(-1+\partial x_{2 \log } / \partial x_{2}\right)}<0$, because $x_{2}\left[x_{1}\right]$ is implicitly

defined as $-x_{2}+x_{2 \log }=0$ where $-\left(-1+\partial x_{2 \log } / \partial x_{2}\right)>0$. Consequently, the sign

of $\frac{d x_{2}}{d x_{1}}$ is the same as the sign of $\partial x_{2 \log } / \partial x_{1}$, which is negative.

The easiest way to determine the sign of $H^{\prime}\left[x_{1}\right]$ is to break up the derivative into parts, which will also help in later proofs using implicit differentiation.

$$
H^{\prime}\left[x_{1}\right]=\frac{\partial H\left[x_{1}\right]}{\partial \theta_{r_{1}}} \cdot \frac{d \theta_{r_{1}}}{d r_{L B, 1}} \cdot \frac{d r_{L B, 1}}{d x_{1}}+\frac{\partial H\left[x_{1}\right]}{\partial r_{L B, 1}} \cdot \frac{d r_{L B, 1}}{d x_{1}}+\frac{\partial H\left[x_{1}\right]}{\partial r_{L B, 2}} \cdot \frac{d r_{L B, 2}}{d x_{2}} \cdot \frac{d x_{2}}{d x_{1}}+\frac{\partial H\left[x_{1}\right]}{\partial x_{1}}
$$


Where, as the above implies, $r_{L B, 1}$ and $r_{L B, 2}$ are fixed in $\frac{\partial H\left[x_{1}\right]}{\partial x_{1}}$.

Clearly, (1) $\frac{d \theta_{r_{1}}}{d r_{L B, 1}} \cdot \frac{d r_{L B, 1}}{d x_{1}}<0$, based on the definition of $\theta_{r_{1}}$ and the equilibrium value of $r_{L B, 1}$ in Proposition 3; (2) $\frac{d r_{L B, 1}}{d x_{1}}<0$ based on the equilibrium value of $r_{L B, 1}$ in Proposition 3; and (3)

$\frac{d r_{L B, 2}}{d x_{2}} \frac{d x_{2}}{d x_{1}}>0$ based on the equilibrium value of $r_{L B, 2}$ in Proposition 3 and $\frac{d x_{2}}{d x_{1}}<0$ shown above.

By inspection of $H\left[x_{1}\right], \frac{\partial H\left[x_{1}\right]}{\partial r_{L B, 1}}>0$ and $\frac{\partial H\left[x_{1}\right]}{\partial r_{L B, 2}}<0$. Thus, all that remains is to show is that

$$
\begin{aligned}
& \frac{\partial H\left[x_{1}\right]}{\partial \theta_{r_{1}}}>0 \text { and } \frac{\partial H\left[x_{1}\right]}{\partial x_{1}}<0 . \\
& \frac{\partial H\left[x_{1}\right]}{\partial \theta_{r_{1}}}=\exp \left[-x_{1}\right]\left(L_{1} r_{L B, 1}+k_{2}\left(1+x_{2}\right)\right)+\partial\left\{k_{2}\left(1-\theta_{r_{1}}\right) \frac{\left(\left(1-\theta_{r_{1}}\right)+\theta_{r_{1}} \exp \left[-x_{1}\right]\right)}{\left.\left(1-\theta_{r_{1}}\right)+\theta_{r_{1}} \exp \left[-x_{1}\right] \exp \left[\lambda_{2} r_{L B, 2}\right]\right) / \partial \theta_{r_{1}}} / \exp \left[-x_{1}\right]\left(\exp \left[x_{1}\right]\left(1-\theta_{r_{1}}\right)+\exp \left[\lambda_{2} r_{L B, 2}\right] \theta_{r_{1}}\right)^{2}\right. \\
& =\exp \left[-x_{1}\right]\left(L_{1} r_{L B, 1}+k_{2}\left(1+x_{2}\right)\right)-\frac{k_{2}\left(\left(\exp \left[x_{1}\right]-1\right)\left(1-\theta_{r_{1}}\right)^{2}+\exp \left[\lambda_{2} r_{L B, 2}\right]\left(1-\theta_{r_{1}}{ }^{2}\right)+\exp \left[\lambda_{2} r_{L B, 2}-x_{1}\right] \theta_{r_{1}}{ }^{2}\right)}{}
\end{aligned}
$$

And our equilibrium condition,

$$
\begin{aligned}
H\left[x_{1}\right]=0 & \Rightarrow \\
& \exp \left[-x_{1}\right]\left(L_{1} r_{L B, 1}+k_{2}\left(1+x_{2}\right)\right)=\frac{1}{\theta_{r_{1}}}\left(-k_{2}\left(1-\theta_{r_{1}}\right) \frac{\left(\left(1-\theta_{r_{1}}\right)+\theta_{r_{1}} \exp \left[-x_{1}\right]\right)}{\left(1-\theta_{r_{1}}\right)+\theta_{r_{1}} \exp \left[-x_{1}\right] \exp \left[\lambda_{2} r_{L B, 2}\right]}+k_{1}\right)
\end{aligned}
$$

Thus, after substituting the above equality, we have

$$
\frac{\partial H\left[x_{1}\right]}{\partial \theta_{r_{1}}}=\frac{\left(k_{1}-k_{2}\right)\left(1-\theta_{r_{1}}\right) \exp \left[x_{1}\right]\left(\exp \left[x_{1}\right]\left(1-\theta_{r_{1}}\right)+2 \exp \left[\lambda_{2} r_{L B, 2}\right] \theta_{r_{1}}\right)+\exp \left[\lambda_{2} r_{L B, 2}\right] \theta_{r_{1}}{ }^{2}\left(\exp \left[\lambda_{2} r_{L B, 2}\right] k_{1}-k_{2}\right)}{\theta_{r_{1}}\left(\exp \left[x_{1}\right]\left(1-\theta_{r_{1}}\right)+\exp \left[\lambda_{2} r_{L B, 2}\right] \theta_{r_{1}}\right)^{2}}>0
$$


because $\left(k_{1}-k_{2}\right)>0$ by assumption.

Next, $\frac{\partial H\left[x_{1}\right]}{\partial x_{1}}=-\theta_{r_{1}} \exp \left[-x_{1}\right]\left(L_{1} r_{L B, 1}+k_{2}\left(1+x_{2}\right)\right)+\theta_{r_{1}} \exp \left[-x_{1}\right] k_{2} \frac{d x_{2}}{d x_{1}}$

$$
+\partial\left\{k_{2}\left(1-\theta_{r_{1}}\right) \frac{\left(\left(1-\theta_{r_{1}}\right)+\theta_{r_{1}} \exp \left[-x_{1}\right]\right)}{\left(1-\theta_{r_{1}}\right)+\theta_{r_{1}} \exp \left[-x_{1}\right] \exp \left[\lambda_{2} r_{L B, 2}\right]}\right\} / \partial x_{1}
$$

Where $\partial\left\{k_{2}\left(1-\theta_{r_{1}}\right) \frac{\left(\left(1-\theta_{r_{1}}\right)+\theta_{r_{1}} \exp \left[-x_{1}\right]\right)}{\left(1-\theta_{r_{1}}\right)+\theta_{r_{1}} \exp \left[-x_{1}\right] \exp \left[\lambda_{2} r_{L B, 2}\right]}\right\} / \partial x_{1}=$

$$
\frac{\left(-1+\exp \left[\lambda_{2} r_{L B, 2}\right]\right) k_{2}\left(1-\theta_{r_{1}}\right)^{2} \theta_{r_{1}}}{\exp \left[-x_{1}\right]\left(\exp \left[x_{1}\right]\left(1-\theta_{r_{1}}\right)+\exp \left[\lambda_{2} r_{L B, 2}\right] \theta_{r_{1}}\right)^{2}}
$$

As before, we substitute for the equilibrium condition that

$$
\theta_{r_{1}} \exp \left[-x_{1}\right]\left(L_{1} r_{L B, 1}+k_{2}\left(1+x_{2}\right)\right)=-k_{2}\left(1-\theta_{r_{1}}\right) \frac{\left(\left(1-\theta_{r_{1}}\right)+\theta_{r_{1}} \exp \left[-x_{1}\right]\right)}{\left(1-\theta_{r_{1}}\right)+\theta_{r_{1}} \exp \left[-x_{1}\right] \exp \left[\lambda_{2} r_{L B, 2}\right]}+k_{1} \text { and }
$$

we get $\frac{\partial H\left[x_{1}\right]}{\partial x_{1}}=\theta_{r_{1}} \exp \left[-x_{1}\right] k_{2} \frac{d x_{2}}{d x_{1}}-$

$$
\frac{\left(k_{1}-k_{2}\left(1-\theta_{r_{1}}\right)\right)\left(1-\theta_{r_{1}}\right) \exp \left[x_{1}\right]\left(\exp \left[x_{1}\right]\left(1-\theta_{r_{1}}\right)+2 \exp \left[\lambda_{2} r_{L B, 2}\right] \theta_{r_{1}}\right)+\theta_{r_{1}}{ }^{2} \exp \left[\lambda_{2} r_{L B, 2}\right]\left(\exp \left[\lambda_{2} r_{L B, 2}\right] k_{1}-k_{2}\left(1-\theta_{r_{1}}\right)\right)}{\left(\exp \left[x_{1}\right]\left(1-\theta_{r_{1}}\right)+\exp \left[\lambda_{2} r_{L B, 2}\right] \theta_{r_{1}}\right)^{2}}<0
$$

Again the above is negative due to $k_{1}-k_{2}>0$ and $\frac{d x_{2}}{d x_{1}}<0$.

Thus, $H^{\prime}\left[x_{1}\right]<0$ and to find the sign of $\frac{d x_{1}}{d g}$ for any parameter $g$, we only need to find the sign of

$\frac{d H\left[x_{1}\right]}{d g}$ because $\frac{d x_{1}}{d g}=\frac{d H\left[x_{1}\right] / d g}{-H^{\prime}\left[x_{1}\right]}$ 
For convenience in later proofs, let

$$
K_{\text {terml }}=\frac{\left(k_{1}-k_{2}\left(1-\theta_{r_{1}}\right)\right)\left(1-\theta_{r_{1}}\right) \exp \left[x_{1}\right]\left(\exp \left[x_{1}\right]\left(1-\theta_{r_{1}}\right)+2 \exp \left[\lambda_{2} r_{L B, 2}\right] \theta_{r_{1}}\right)+\theta_{r_{1}}{ }^{2} \exp \left[\lambda_{2} r_{L B, 2}\right]\left(\exp \left[\lambda_{2} r_{L B, 2}\right] k_{1}-k_{2}\left(1-\theta_{r_{1}}\right)\right)}{\left(\exp \left[x_{1}\right]\left(1-\theta_{r_{1}}\right)+\exp \left[\lambda_{2} r_{L B, 2}\right] \theta_{r_{1}}\right)^{2}}
$$

and

$$
\begin{gathered}
K_{\text {term } 2}=\frac{\left(k_{1}-k_{2}\right)\left(1-\theta_{r_{1}}\right) \exp \left[x_{1}\right]\left(\exp \left[x_{1}\right]\left(1-\theta_{r_{1}}\right)+2 \exp \left[\lambda_{2} r_{L B, 2}\right] \theta_{r_{1}}\right)+\exp \left[\lambda_{2} r_{L B, 2}\right] \theta_{r_{1}}{ }^{2}\left(\exp \left[\lambda_{2} r_{L B, 2}\right] k_{1}-k_{2}\right)}{\theta_{r_{1}}\left(\exp \left[x_{1}\right]\left(1-\theta_{r_{1}}\right)+\exp \left[\lambda_{2} r_{L B, 2}\right] \theta_{r_{r_{1}}}\right)^{2}} \\
\text { Thus, } K_{\text {term }}-\theta_{r_{1}} K_{t w r m 2}=\frac{k_{2} \theta_{r_{1}}\left(\exp \left[2 x_{1}\right]\left(1-\theta_{r_{1}}\right)^{2}+2 \exp \left[x_{1}+\lambda_{2} r_{L B, 2}\right]\left(1-\theta_{r_{1}}\right) \theta_{r_{1}}+\exp \left[\lambda_{2} r_{L B, 2}\right] \theta_{r_{1}}^{2}\right)}{\left(\exp \left[x_{1}\right]\left(1-\theta_{r_{1}}\right)+\exp \left[\lambda_{2} r_{L B, 2}\right] \theta_{r_{1}}\right)^{2}}>0 .
\end{gathered}
$$

And we have, noting that $\frac{d \theta_{r_{1}}}{d r_{L B, 1}} \cdot \frac{d r_{L B, 1}}{d x_{1}}=\frac{d \theta_{r_{1}}}{d x_{1}}$,

$H^{\prime}\left[x_{1}\right]=K_{\text {term } 2} \frac{d \theta_{r_{1}}}{d x_{1}}+\frac{\partial H\left[x_{1}\right]}{\partial r_{L B, 1}} \frac{d r_{L B, 1}}{d x_{1}}+\frac{\partial H\left[x_{1}\right]}{\partial r_{L B, 2}} \frac{d r_{L B, 2}}{d x_{2}} \frac{d x_{2}}{d x_{1}}+\theta_{r_{1}} \exp \left[-x_{1}\right] k_{2} \frac{d x_{2}}{d x_{1}}-K_{\text {term } 1}<0$

Proof of $\frac{d x_{1}}{d L_{1}}>0, \frac{d x_{1}}{d k_{1}}<0, \frac{d r_{L B, 1}}{d L_{1}}<0$, and $\frac{d r_{L B, 1}}{d k_{1}}>0$

$\frac{\partial H\left[x_{1}\right]}{\partial L_{1}}=\theta_{r_{1}} \exp \left[-x_{1}\right] r_{L B, 1}>0$ and $\frac{d r_{L B, 1}}{d L_{1}}=r_{L B, 1} \frac{-\exp \left[x_{1}\right]}{-1+\exp \left[x_{1}\right]} \frac{d x_{1}}{d L_{1}}<0$

$\frac{\partial H\left[x_{1}\right]}{\partial k_{1}}=-1<0$ and $\frac{d r_{L B, 1}}{d k_{1}}=r_{L B, 1} \frac{-\exp \left[x_{1}\right]}{-1+\exp \left[x_{1}\right]} \frac{d x_{1}}{d k_{1}}>0$

Proof of $\frac{d x_{1}}{d R_{1}}>0, \frac{d x_{1}}{d p_{1}}<0, \frac{d r_{L B, 1}}{d R_{1}}>0$, and $\frac{d r_{L B, 1}}{d p_{1}}<0$

$\frac{\partial H\left[x_{1}\right]}{\partial R_{1}}=\frac{\partial H\left[x_{1}\right]}{\partial \theta_{r_{1}}} \frac{d \theta_{r_{1}}}{d r_{L B, 1}} \frac{\partial r_{L B, 1}}{\partial R_{1}}+\frac{\partial H\left[x_{1}\right]}{\partial r_{L B, 1}} \frac{\partial r_{L B, 1}}{\partial R_{1}}+\frac{\partial H\left[x_{1}\right]}{\partial r_{L B, 2}} \frac{d r_{L B, 2}}{d x_{2}} \frac{\partial x_{2}}{\partial r_{L B, 1}} \frac{\partial r_{L B, 1}}{\partial R_{1}}+\frac{\partial H\left[x_{1}\right]}{\partial x_{2}} \frac{\partial x_{2}}{\partial r_{L B, 1}} \frac{\partial r_{L B, 1}}{\partial R_{1}}>0$ 
where $\frac{\partial x_{2}}{\partial r_{L B, 1}}=\frac{\partial x_{2 \log } / \partial r_{L B, 1}}{-\left(-1+\partial x_{2 \log } / \partial x_{2}\right)}>0$ and each of the other terms' signs were previously

established.

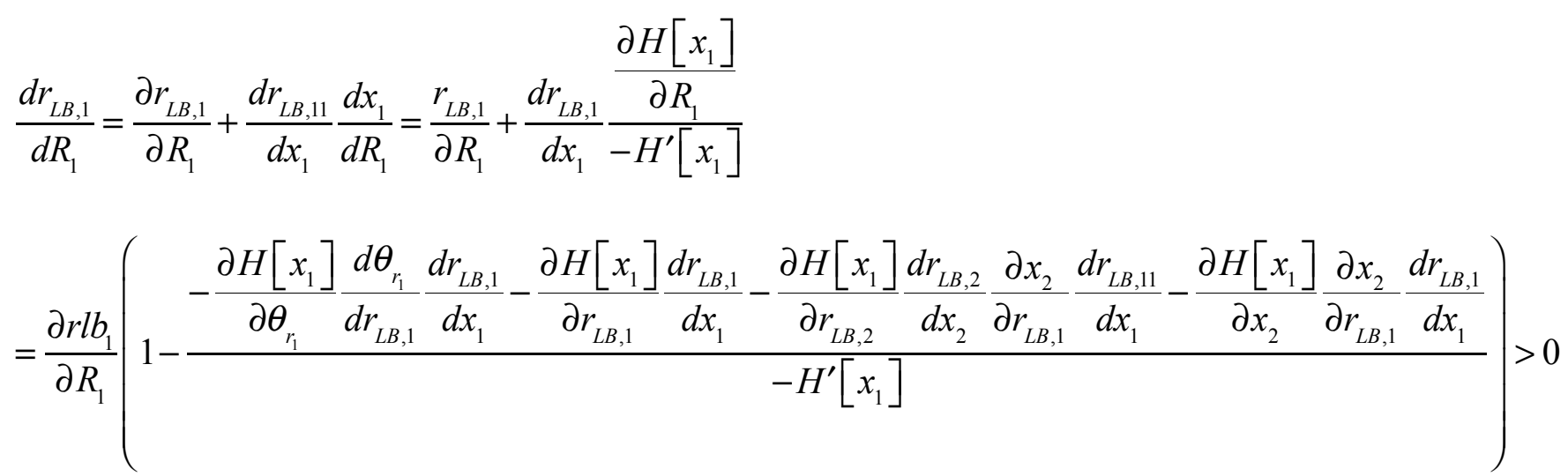

because $-\frac{\partial x_{2}}{\partial r_{L B, 1}} \frac{d r_{L B, 1}}{d x_{1}}<-\frac{d x_{2}}{d x_{1}}$. Thus, the numerator of the second term in parentheses is less than the denominator so that the term in the parenthesis is positive, The proofs for $\frac{d x_{1}}{d p_{1}}<0$ and $\frac{d r_{L B, 1}}{d p_{1}}<0$ are similar.

Proof of $\frac{d x_{1}}{d \lambda_{1}}>0$ and $\frac{d r_{L B, 1}}{d \lambda_{1}}<0$

$\frac{\partial H\left[x_{1}\right]}{\partial \lambda_{1}}=\left\{\frac{\partial H\left[x_{1}\right]}{\partial \theta_{r_{1}}}+\theta_{r_{1}} \exp \left[-x_{1}\right] k_{2} \frac{\partial x_{2}}{\partial \theta_{r_{1}}}+\frac{\partial H\left[x_{1}\right]}{\partial r_{L B, 2}} \frac{d r_{L B, 2}}{d x_{2}} \frac{\partial x_{2}}{\partial \theta_{r_{1}}}\right\} \frac{d \theta_{r_{1}}}{d \lambda_{1}}>0$

where $\frac{\partial x_{2}}{\partial \theta_{r_{1}}}=\frac{\partial x_{2 \log } / \partial \theta_{r_{1}}}{-\left(-1+\partial x_{2 \log } / \partial x_{2}\right)}>0$, with $\frac{\partial H\left[x_{1}\right]}{\partial \theta_{r_{1}}}>0, \frac{\partial x_{2 \log } / \theta_{r_{1}}}{-\left(-1+\partial x_{2 \log } / \partial x_{2}\right)}>0$ and $\frac{d \theta_{r_{1}}}{d \lambda_{1}}>0$.

It follows that $\frac{d r_{L B, 1}}{d \lambda_{1}}<0$.

Proof of $\frac{d x_{1}}{d L_{2}}>0$ and $\frac{d r_{L B, 1}}{d L_{2}}<0$

$\frac{\partial H\left[x_{1}\right]}{\partial L_{2}}=\theta_{r_{1}} \exp \left[-x_{1}\right] k_{2} \frac{\partial x_{2}}{\partial L_{2}}+\frac{\partial H\left[x_{1}\right]}{\partial r_{L B, 2}} \frac{d r_{L B, 2}}{d x_{2}} \frac{\partial x_{2}}{\partial L_{2}}>0$ where $\frac{\partial x_{2}}{\partial L_{2}}=\frac{\partial x_{2 \log } / \partial L_{2}}{-\left(-1+\partial x_{2 \log } / \partial x_{2}\right)}>0$

It follows that $\frac{d r_{L B, 1}}{d L_{2}}<0$ because $\frac{d r_{L B, 1}}{d x_{1}}<0$. 


$$
\begin{aligned}
& \text { Proof of } \frac{d x_{1}}{d k_{2}}>0 \text { and } \frac{d r_{L B, 1}}{d k_{2}}<0 \\
& \frac{\partial H\left[x_{1}\right]}{\partial k_{2}}=\theta_{r_{1}} \exp \left[-x_{1}\right]\left(k_{2} \frac{\partial x_{2}}{\partial k_{2}}+1+x_{2}\right)+\left(1-\theta_{r_{1}}\right) \frac{\left(\left(1-\theta_{r_{1}}\right)+\theta_{r_{1}} \exp \left[-x_{1}\right]\right)}{\left(1-\theta_{r_{1}}\right)+\theta_{r_{1}} \exp \left[-x_{1}\right] \exp \left[\lambda_{2} r_{L B, 2}\right]}+\frac{\partial H\left[x_{1}\right]}{\partial r_{L B, 2}} \frac{d r_{L B, 2}}{d k_{2}} \\
& \text { (where } \left.\frac{d r_{L B, 2}}{d k_{2}}=\frac{d r_{L B, 2}}{d x_{2}} \frac{\partial x_{2 \log } / \partial k_{2}}{-\left(-1+\partial x_{2 \log } / \partial x_{2}\right)}>0, \text { with }-\left(-1+\partial x_{2 \log } / \partial x_{2}\right)>1\right) \\
& =\theta_{r_{1}} \exp \left[-x_{1}\right]\left(k_{2} \frac{-1 / k_{2}}{-\left(-1+\partial x_{2 \log } / \partial x_{2}\right)}+1+x_{2}\right)+\left(1-\theta_{r_{1}}\right) \frac{\left(\left(1-\theta_{r_{1}}\right)+\theta_{r_{1}} \exp \left[-x_{1}\right]\right)}{\left(1-\theta_{r_{1}}\right)+\theta_{r_{1}} \exp \left[-x_{1}\right] \exp \left[\lambda_{2} r_{L B, 2}\right]}+\frac{\partial H\left[x_{1}\right]}{\partial r_{L B, 2}} \frac{d r_{L B, 2}}{d k_{2}} \\
& =\theta_{r_{1}} \exp \left[-x_{1}\right]\left(\frac{-1}{-\left(-1+\partial x_{2 \log } / \partial x_{2}\right)}+1+x_{2}\right) \\
& +\left(\frac{-\exp \left[x_{2}\right] r_{L B, 2} \lambda_{2} \theta_{r_{1}} \exp \left[r_{L B, 2} \lambda_{2}\right]}{-\left(-1+\partial x_{2 L o g} / \partial x_{2}\right)\left(-1+\exp \left[x_{2}\right]\right)\left(\exp \left[x_{2}\right]\left(1-\theta_{r_{1}}\right)+\exp \left[r_{L B, 2} \lambda_{2}\right] \theta_{r_{1}}\right)}+1\right)\left(\frac{\left(\exp \left[x_{1}\right]\left(1-\theta_{r_{1}}\right)+\theta_{r_{1}}\right)\left(1-\theta_{r_{1}}\right)}{\exp \left[x_{1}\right]\left(1-\theta_{r_{1}}\right)+\exp \left[r_{L B, 2} \lambda_{2}\right] \theta_{r_{1}}}\right)>0 \\
& \text { where } \frac{\exp \left[x_{2}\right] r_{L B, 2} \lambda_{2} \theta_{r_{1}} \exp \left[r_{L B, 2} \lambda_{2}\right]}{-\left(-1+\partial x_{2 \log } / \partial x_{2}\right)\left(-1+\exp \left[x_{2}\right]\right)\left(\exp \left[x_{2}\right]\left(1-\theta_{r_{1}}\right)+\exp \left[r_{L B, 2} \lambda_{2}\right] \theta_{r_{1}}\right)} \\
& =\frac{\exp \left[x_{2}+r_{L B, 2} \lambda_{2}\right] \theta_{r_{1}} r_{L B, 2} \lambda_{2}}{\left(\exp \left[x_{1}\right]\left(1-\theta_{r_{1}}\right)+\exp \left[r_{L B, 2} \lambda_{2}\right] \theta_{r_{1}}\right)\left(-1+\exp \left[x_{2}\right]\right)+\exp \left[x_{2}+r_{L B, 2} \lambda_{2}\right] \theta_{r_{1}}+\exp \left[x_{2}+x_{1}\right]\left(1-\theta_{r_{1}}\right)\left(1+r_{L B, 2} \lambda_{2}\right)}<1
\end{aligned}
$$$$
\text { because we assume } r_{L B, 2} \lambda_{2}=\frac{r_{L B, 2}}{1 / \lambda_{2}}<1 \text {, and thus } \frac{d x_{1}}{d k_{2}}>0 \text {. It follows that also } \frac{d r_{L B, 1}}{d k_{2}}<0 \text {. }
$$$$
\text { Proof of } \frac{d x_{1}}{d R_{2}}>0, \frac{d x_{1}}{d p_{2}}<0, \frac{d r_{L B, 1}}{d R_{2}}<0 \text { and } \frac{d r_{L B, 1}}{d p_{2}}>0
$$$$
\frac{\partial H\left[x_{1}\right]}{\partial R_{2}}=\frac{\partial H\left[x_{1}\right]}{\partial r_{L B, 2}} \frac{d r_{L B, 2}}{d R_{2}}+\frac{\partial H\left[x_{1}\right]}{\partial x_{2}} \frac{\partial x_{2 \log } / \partial r_{L B, 2}}{-\left(-1+\partial x_{2 \log } / \partial x_{2}\right)} \frac{d r_{L B, 2}}{d R_{2}}+\frac{\partial H\left[x_{1}\right]}{\partial r_{L B, 2}} \frac{d r_{L B, 2}}{d x_{2}} \frac{\partial x_{2 \log } / \partial r_{L B, 2}}{-\left(-1+\partial x_{2 \log } / \partial x_{2}\right)} \frac{d r_{L B, 2}}{d R_{2}}
$$ 


$$
\begin{aligned}
& =\frac{d r_{L B, 2}}{d R_{2}}\left\{\frac{\partial H\left[x_{1}\right]}{\partial r_{L B, 2}}+\frac{\partial H\left[x_{1}\right]}{\partial x_{2}} \frac{\partial x_{2 \log } / \partial r_{L B, 2}}{-\left(-1+\partial x_{2 \log } / \partial x_{2}\right)}+\frac{\partial H\left[x_{1}\right]}{\partial r_{L B, 2}} \frac{d r_{L B, 2}}{d x_{2}} \frac{\partial x_{2 \log } / \partial r_{L B, 2}}{-\left(-1+\partial x_{2 \log } / \partial x_{2}\right)}\right\} \\
& =\frac{d r_{L B, 2}}{d R_{2}} \frac{\partial x_{2}}{\partial r_{L B, 2}} \frac{\exp \left[-x_{1}\right] k_{2} \theta_{r_{1}}\left(2 \exp \left[x_{1}+r_{L B, 2} \lambda_{2}\right]\left(1-\theta_{r_{1}}\right) \theta_{r_{1}}+\exp \left[2 r_{L B, 2} \lambda_{2}\right] \theta_{r_{1}}{ }^{2}-\exp \left[2 x_{1}\right]\left(1-\theta_{r_{1}}\right)^{2}\left(-1+\frac{\left(-1+\exp \left[r_{L B, 2} \lambda \lambda_{2}\right]\right) R_{2} \lambda_{2}}{\left(-1+\exp \left[x_{2}\right]\right) p_{2}}\right)\right)}{\left(\exp \left[x_{1}\right](1-\theta 1)+\exp \left[r_{L B, 2} \lambda_{2}\right] \theta_{r_{1}}\right)\left(\exp \left[x_{1}+r_{L B, 2} \lambda_{2}\right] \theta_{r_{1}}+\exp \left[x_{1}\right]\left(1-\theta_{r_{1}}\right)\left(1+r_{L B, 2} \lambda_{2}\right)\right)}>0 \\
& \text { Because } \frac{\left(-1+\exp \left[r_{L B, 2} \lambda_{2}\right]\right) R_{2} \lambda_{2}}{\left(-1+\exp \left[x_{2}\right]\right) p_{2}}<1 \text { as long as } \frac{L_{2}}{k_{2}} \text { is large enough implying large } x_{2} \text { and smaller } \\
& r_{L B, 2} \lambda_{2} \text {. We also verified this result through numerical analysis. Similarly, we find that } \frac{d x_{1}}{d p_{2}}<0 \text {. } \\
& \text { Also, } \frac{d r_{L B, 1}}{d R_{2}}=\frac{\partial r_{L B, 1}}{\partial R_{2}}+\frac{d r_{L B, 1}}{d x_{1}} \frac{d x_{1}}{d R_{2}}=0+\frac{d r_{L B, 1}}{d x_{1}} \frac{d x_{1}}{d R_{2}}<0 \text {, and similarly, } \\
& \frac{d r_{L B, 1}}{d p_{2}}=\frac{\partial r_{L B, 1}}{\partial p_{2}}+\frac{d r_{L B, 1}}{d x_{1}} \frac{d x_{1}}{d p_{2}}=0+\frac{d r_{L B, 1}}{d x_{1}} \frac{d x_{1}}{d p_{2}}>0 \\
& \text { Proof of } \frac{d x_{1}}{d \lambda_{2}}<0 \text { and } \frac{d r_{L B, 1}}{d \lambda_{2}}>0 \\
& \frac{d H\left[x_{1}\right]}{d \lambda_{2}}=\theta_{r_{1}} \exp \left[-x_{1}\right] k_{2} \frac{\partial x_{2}}{\partial \lambda_{2}}+\frac{\partial H\left[x_{1}\right]}{\partial \lambda_{2}}+\frac{\partial H\left[x_{1}\right]}{\partial r_{L B, 2}} \frac{d r_{L B, 2}}{d x_{2}} \frac{\partial x_{2}}{\partial \lambda_{2}} \text { where } \frac{\partial x_{2}}{\partial \lambda_{2}}=\frac{\partial x_{2 \log } / \lambda_{2}}{-\left(-1+\partial x_{2 \log } / \partial x_{2}\right)}>0 \\
& =-\frac{\exp \left[-x_{1}\right] k_{2} \theta_{r_{1}}\left(\exp \left[x_{1}\right]\left(1+\exp \left[x_{2}\right]\left(-1+\exp \left[r_{L B, 2} \lambda_{2}\right]\right)+\exp \left[r_{L B, 2} \lambda_{2}\right]\left(-1+\exp \left[x_{2}\right]\right)\right)\left(1-\theta_{r_{1}}\right)+\exp \left[x_{2}+r_{L B, 2} \lambda_{2}\right] \theta_{r_{1}}\right)}{\left(-1+\exp \left[x_{2}\right]\right)\left(\exp \left[x_{1}\right]\left(1-\theta_{r_{1}}\right)+\exp \left[r_{L B, 2} \lambda_{2}\right] \theta_{r_{1}}\right)} \frac{\partial x_{2}}{\partial \lambda_{2}}<0
\end{aligned}
$$

And it follows that $\frac{d r_{L B, 1}}{d \lambda_{2}}>0$.

Proof of $\frac{d x_{2}}{d L_{1}}<0, \frac{d x_{2}}{d k_{1}}>0, \frac{d r_{L B, 2}}{d L_{1}}>0$ and $\frac{d r_{L B, 2}}{d k_{1}}<0$

$$
\frac{d x_{2}}{d L_{1}}=\frac{\partial x_{2 \log } / \partial L_{1}}{-\left(-1+\partial x_{2 \log } / \partial x_{2}\right)}+\frac{\partial x_{2 \log } / \partial x_{1}}{-\left(-1+\partial x_{2 \log } / \partial x_{2}\right)} \frac{d x_{1}}{d L_{1}}<0 \text { where } \frac{\partial x_{2 \log }}{\partial L_{1}}=0
$$


$\frac{d x_{2}}{d k_{1}}=\frac{\partial x_{2 \log } / \partial k_{1}}{-\left(-1+\partial x_{2 \log } / \partial x_{2}\right)}+\frac{\partial x_{2 \log } / \partial x_{1}}{-\left(-1+\partial x_{2 \log } / \partial x_{2}\right)} \frac{d x_{1}}{d k_{1}}>0$ where $\frac{\partial x_{2 \log }}{\partial k_{1}}=0$

It follows that $\frac{d r_{L B, 2}}{d L_{1}}>0$ and $\frac{d r_{L B, 2}}{d k_{1}}<0$.

Proof of $\frac{d x_{2}}{d R_{1}}<0, \frac{d x_{2}}{d p_{1}}>0, \frac{d r_{L B, 2}}{d R_{1}}>0$ and $\frac{d r_{L B, 2}}{d p_{1}}<0$

$\frac{d x_{2}}{d R_{1}}=\frac{\partial x_{2}}{\partial R_{1}}+\frac{d x_{2}}{d x_{1}} \frac{d x_{1}}{d R_{1}}$

$\frac{d x_{2}}{d R_{1}}=\frac{\partial x_{2}}{\partial R_{1}}+\frac{d x_{2}}{d x_{1}} \frac{\frac{\partial H\left[x_{1}\right]}{\partial \theta_{r_{1}}} \frac{d \theta_{r_{1}}}{d r_{L B, 1}} \frac{\partial r_{L B, 1}}{\partial R_{1}}+\frac{\partial H\left[x_{1}\right]}{\partial r_{L B, 1}} \frac{\partial r_{L B, 1}}{\partial R_{1}}+\frac{\partial H\left[x_{1}\right]}{\partial r_{L B, 2}} \frac{d r_{L B, 2}}{d x_{2}} \frac{\partial x_{2}}{\partial r_{L B, 1}} \frac{\partial r_{L B, 11}}{\partial R_{1}}+\frac{\partial H\left[x_{1}\right]}{\partial x_{2}} \frac{\partial x_{2}}{\partial r_{L B, 1}} \frac{\partial r_{L B, 1}}{\partial R_{1}}}{-H^{\prime}\left[x_{1}\right]}$

$=\frac{\partial r_{L B, 1}}{\partial R_{1}}\left\{\frac{\partial x_{2}}{\partial r_{L B, 1}}+\frac{d x_{2}}{d x_{1}} \frac{\frac{\partial H\left[x_{1}\right]}{\partial \theta_{r_{1}}} \frac{d \theta_{r_{1}}}{d r_{L B, 1}}+\frac{\partial x_{2}}{\partial r_{L B, 1}}\left(\frac{\partial H\left[x_{1}\right]}{\partial r_{L B, 2}} \frac{d r_{L B, 2}}{d x_{2}}+\frac{\partial H\left[x_{1}\right]}{\partial x_{2}}\right)+\theta_{r_{1}} \exp \left[-x_{1}\right] L_{1}}{-H^{\prime}\left[x_{1}\right]}\right\}$

Working within the brackets where $\frac{\partial r_{L B, 1}}{\partial R_{1}}>0$, we have the following.

$$
\begin{aligned}
& \left(\frac{\partial x_{2}}{\partial r_{L B, 1}}\left(-H^{\prime}\left[x_{1}\right]\right)+\frac{d x_{2}}{d x_{1}}\left(\frac{\partial H\left[x_{1}\right]}{\partial \theta_{r_{1}}} \frac{d \theta_{r_{1}}}{d r_{L B, 1}}+\frac{\partial H\left[x_{1}\right]}{\partial r_{L B, 1}}+\frac{\partial H\left[x_{1}\right]}{\partial r_{L B, 2}} \frac{d r_{L B, 2}}{d x_{2}} \frac{\partial x_{2}}{\partial r_{L B, 1}}+\frac{\partial H\left[x_{1}\right]}{\partial x_{2}} \frac{\partial x_{2}}{\partial r_{L B, 1}}\right)\right) \\
= & \left(\frac{\partial x_{2}}{\partial r_{L B, 1}}\left(-H^{\prime}\left[x_{1}\right]\right)+\left(\frac{\partial H\left[x_{1}\right]}{\partial \theta_{r_{1}}} \frac{d \theta_{r_{1}}}{d r_{L B, 1}} \frac{d x_{2}}{d x_{1}}+\frac{\partial H\left[x_{1}\right]}{\partial r_{L B, 1}} \frac{d x_{2}}{d x_{1}}+\frac{\partial H\left[x_{1}\right]}{\partial r_{L B, 2}} \frac{d r_{L B, 2}}{d x_{2}} \frac{\partial x_{2}}{\partial r_{L B, 1}} \frac{d x_{2}}{d x_{1}}+\frac{\partial H\left[x_{1}\right]}{\partial x_{2}} \frac{\partial x_{2}}{\partial r_{L B, 1}} \frac{d x_{2}}{d x_{1}}\right)\right) \\
= & -\left\{\frac{\partial H\left[x_{1}\right]}{\partial \theta_{r_{1}}} \cdot \frac{d \theta_{r_{1}}}{d r_{L B, 1}} \cdot \frac{d r_{L B, 1}}{d x_{1}} \frac{\partial x_{2 \log } / \partial r_{L B, 1}}{D e n o m}+\frac{\partial H\left[x_{1}\right]}{\partial r_{L B, 1}} \cdot \frac{d r_{L B, 1}}{d x_{1}} \frac{\partial x_{2 \log } / \partial r_{L B, 1}}{\text { Denom }}+\left(-K_{\text {term }}\right) \frac{\partial x_{2 \log } / \partial r_{L B, 1}}{\text { Denom }}\right\} \\
& +\left(\frac{\partial H\left[x_{1}\right]}{\partial \theta_{r_{1}}} \frac{d \theta_{r_{1}}}{d r_{L B, 1}} \frac{d x_{2 \log } / d x_{1}}{\text { Denom }}+\frac{\partial H\left[x_{1}\right]}{\partial r_{L B, 1}} \frac{d x_{2 \log } / d x_{1}}{\text { Denom }}\right), \quad \text { where Denom }=-\left(-1+\partial x_{2 L o g} / \partial x_{2}\right)
\end{aligned}
$$

Note that $\frac{d x_{2 \log } / d x_{1}}{\text { Denom }}=\frac{d r_{L B, 1}}{d x_{1}} \frac{\partial x_{2 \log } / \partial r_{L B, 1}}{\text { Denom }}+\frac{\partial x_{2 \log } / \partial x_{1}}{\text { Denom }}$ 


$$
\begin{aligned}
& =\frac{1}{\text { Denom }}\left\{K_{\text {term } 1} \frac{\partial x_{2 \log }}{\partial r_{L B, 1}}+K_{\text {term } 2} \frac{d \theta_{r_{1}}}{d r_{L B, 1}}\left(\frac{\partial x_{2 \log }}{\partial x_{1}}\right)+\frac{\partial H\left[x_{1}\right]}{\partial r_{L B, 1}}\left(\frac{\partial x_{2 \log }}{\partial x_{1}}\right)\right\} \\
= & \frac{-\exp \left[r_{L B, 1} \lambda_{1}\right](1-\theta) \theta\left(L_{1}-\exp \left[x_{1}\right] k_{1} \lambda_{1}\right)}{\left(\exp \left[x_{1}\right](1-\theta)+\exp \left[r_{L B, 1} \lambda_{1}+r_{L B, 2} \lambda_{2}\right] \theta\right)\left(1+\left(-1+\exp \left[r_{L B, 1} \lambda_{1}\right]\right) \theta\right)}<0 \text { as long as }
\end{aligned}
$$

$\left(L_{1}-\exp \left[x_{1}\right] k_{1} \lambda_{1}\right)>0$, which is equivalent to $\frac{\exp \left[-x_{1}\right] L_{1}}{k_{1} \lambda_{1}}>1$ and we see from $H\left[x_{1}\right]=0$ that for small $k_{2}<k_{1}$ that $\frac{\exp \left[-x_{1}\right] L_{1} r_{L B, 1}}{k_{1}}=\frac{1}{\theta_{r_{1}}}>1>r_{L B, 1} \lambda_{1}$ (by assumption $r_{L B, 1} \lambda_{1}<1$ ). Thus, $\frac{\exp \left[-x_{1}\right] L_{1}}{k_{1} \lambda_{1}}>1$

Furthermore, we could find no numerical examples where this didn't hold.

$\frac{d x_{2}}{d p_{1}}>0$ is ahown in a similar fashion.

$\frac{d r_{L B, 2}}{d R_{1}}=\frac{\partial r_{L B, 2}}{\partial R_{1}}+\frac{d r_{L B, 2}}{d x_{2}} \frac{d x_{2}}{d R_{1}}=0+\frac{d r_{L B, 2}}{d x_{2}} \frac{d x_{2}}{d R_{1}}>0$ and similarly, $\frac{d r_{L B, 2}}{d p_{1}}<0$

Proof of $\frac{d x_{2}}{d \lambda_{1}}>0$ and $\frac{d r_{L B, 2}}{d \lambda_{1}}<0$

$\frac{d x_{2}}{d \lambda_{1}}=\left(\frac{\partial x_{2}}{\partial \theta_{r_{1}}}+\frac{d x_{2}}{d x_{1}} \frac{\partial H\left[x_{1}\right] / \partial \theta_{r_{1}}}{-H^{\prime}\left[x_{1}\right]}\right) \frac{d \theta_{r_{1}}}{d \lambda_{1}}=\left\{\frac{\partial x_{2}}{\partial \theta_{r_{1}}}+\frac{d x_{2}}{d x_{1}} \frac{\frac{\partial H\left[x_{1}\right]}{\partial \theta_{r_{1}}}+\theta_{r_{1}} \exp \left[-x_{1}\right] k_{2} \frac{\partial x_{2}}{\partial \theta_{r_{1}}}+\frac{\partial H\left[x_{1}\right]}{\partial r_{L B, 2}} \frac{d r_{L B, 2}}{d x_{2}} \frac{\partial x_{2}}{\partial \theta_{r_{1}}}}{-H^{\prime}\left[x_{1}\right]}\right\} \frac{d \theta_{r_{r_{1}}}}{d \lambda_{1}}$

where $\frac{\partial x_{2}}{\partial \theta_{r_{1}}}=\frac{\partial x_{2 \log } / \theta_{r_{1}}}{-\left(-1+\partial x_{2 \log } / \partial x_{2}\right)}>0$ and $\frac{d x_{2}}{d x_{1}}=\frac{\frac{\partial x_{2 \log }}{\partial \theta_{r_{1}}} \frac{\partial \theta_{r_{1}}}{\partial x_{1}}+\frac{\partial x_{2 \log }}{\partial x_{1}}}{-\left(-1+\partial x_{2 \log } / \partial x_{2}\right)}<0$

Thus, we have $\frac{d x_{2}}{d \lambda_{1}}=\frac{\partial x_{2}}{\partial \theta_{r_{1}}}\left\{1+\frac{d x_{2}}{d x_{1}} \frac{\frac{\partial H\left[x_{1}\right]}{\partial \theta_{r_{1}}} / \frac{\partial x_{2}}{\partial \theta_{r_{1}}}+\theta_{r_{1}} \exp \left[-x_{1}\right] k_{2}+\frac{\partial H\left[x_{1}\right]}{\partial r_{L B, 2}} \frac{d r_{L B, 2}}{d x_{2}}}{-H^{\prime}\left[x_{1}\right]}\right\} \frac{d \theta_{r_{1}}}{d \lambda_{1}}$ 


$$
\begin{aligned}
= & \frac{\partial x_{2}}{\partial \theta_{r_{1}}}\left\{1+\frac{\frac{\partial x_{2 \log }}{\partial \theta_{r_{1}}} \frac{\partial \theta_{r_{1}}}{\partial x_{1}}+\frac{\partial x_{2 \log }}{\partial x_{1}} \frac{\partial H\left[x_{1}\right]}{\partial \theta_{r_{1}}}+\theta_{r_{1}} \exp \left[-x_{1}\right] k_{2} \frac{d x_{2}}{d x_{1}}+\frac{\partial H\left[x_{1}\right]}{\partial r_{L B, 2}} \frac{d r_{L B, 2}}{d x_{2}} \frac{d x_{2}}{d x_{1}}}{-H^{\prime}\left[x_{1}\right]}\right\} \frac{d \theta_{r_{1}}}{d \lambda_{1}} \\
= & \frac{\partial x_{2}}{\partial \theta_{r_{1}}}\left\{1-\frac{\partial H\left[x_{1}\right]}{\partial \theta_{r_{1}}} \frac{\partial \theta_{r_{1}}}{\partial x_{1}}-\frac{\partial H\left[x_{1}\right]}{\partial r_{L B, 2}} \frac{d r_{L B, 2}}{d x_{2}} \frac{d x_{2}}{d x_{1}}-\theta_{r_{1}} \exp \left[-x_{1}\right] k_{2} \frac{d x_{2}}{d x_{1}}+\left(\theta_{r_{1}}\left(1-\theta_{r_{1}}\right)\right) \frac{\partial H\left[x_{1}\right]}{\partial \theta_{r_{1}}}\right. \\
-H^{\prime}\left[x_{1}\right] & \frac{\partial \theta_{r_{1}}}{d \lambda_{1}}>0
\end{aligned}
$$

because as shown above $-H^{\prime}\left[x_{1}\right]>0$ and $\left(\left(1-\theta_{r_{1}}\right) \theta_{r_{1}}\right) \frac{\partial H\left[x_{1}\right]}{\partial \theta_{r_{1}}}=\left(1-\theta_{r_{1}}\right) \theta_{r_{1}} K_{\text {term } 2}<\theta_{r_{1}} K_{\text {term } 2}<K_{\text {term } 1}$.

Thus, referring to (A1) above,

$$
\frac{-K_{\text {term } 2} \frac{d \theta_{r_{1}}}{d x_{1}}-\frac{\partial H\left[x_{1}\right]}{\partial r_{L B, 2}} \frac{d r_{L B, 2}}{d x_{2}} \frac{d x_{2}}{d x_{1}}-\theta_{r_{1}} \exp \left[-x_{1}\right] k_{2} \frac{d x_{2}}{d x_{1}}+\theta_{r_{1}}\left(1-\theta_{r_{1}}\right) K_{\text {term } 2}}{-H^{\prime}\left[x_{1}\right]}<1 \text {. Thus, } \frac{d x_{2}}{d \lambda_{1}}>0 .
$$

It also follows that $\frac{d r_{L B, 2}}{d \lambda_{1}}<0$.

Proof of $\frac{d x_{2}}{d L_{2}}>0, \frac{d x_{2}}{d k_{2}}<0, \frac{d r_{L B, 2}}{d L_{2}}<0$ and $\frac{d r_{L B, 2}}{d k_{2}}>0$

$\frac{d x_{2}}{d L_{2}}=\frac{\partial x_{2}}{\partial L_{2}}+\frac{d x_{2}}{d x_{1}} \frac{\partial H\left[x_{1}\right] / \partial L_{2}}{-H^{\prime}\left[x_{1}\right]}$

$=\frac{\partial x_{2 \log } / \partial L_{2}}{-\left(-1+\partial x_{2 \log } / \partial x_{2}\right)}+\frac{d x_{2}}{d x_{1}} \frac{\left(\theta_{r_{1}} \exp \left[-x_{1}\right] k_{2}+\frac{\partial H\left[x_{1}\right]}{\partial r_{L B, 2}} \frac{\partial r_{L B, 2}}{\partial x_{2}}\right) \frac{\partial x_{2 \log } / L_{2}}{-\left(-1+\partial x_{2 \log } / \partial x_{2}\right)}}{-H^{\prime}\left[x_{1}\right]}$

$=\frac{\partial x_{2 \log } / \partial L_{2}}{-\left(-1+\partial x_{2 \log } / \partial x_{2}\right)}\left\{1-\frac{-\left(\theta_{r_{1}} \exp \left[-x_{1}\right] k_{2}+\frac{\partial H\left[x_{1}\right]}{\partial r_{L B, 2}} \frac{\partial r_{L B, 2}}{\partial x_{2}}\right) \frac{d x_{2}}{d x_{1}}}{-H^{\prime}\left[x_{1}\right]}\right\}>0$ 
because $-\left(\theta_{r_{1}} \exp \left[-x_{1}\right] k_{2}+\frac{\partial H\left[x_{1}\right]}{\partial r_{L B, 2}} \frac{\partial r_{L B, 2}}{\partial x_{2}}\right) \frac{d x_{2}}{d x_{1}}<-H^{\prime}\left[x_{1}\right]$.

$\frac{d x_{2}}{d k_{2}}=\frac{\partial x_{2}}{\partial k_{2}}+\frac{d x_{2}}{d x_{1}} \frac{\partial H\left[x_{1}\right] / \partial k_{2}}{-H^{\prime}\left[x_{1}\right]}=$

$=\frac{\partial x_{2}}{\partial k_{2}}+\frac{d x_{2}}{d x_{1}} \cdot\left(\frac{\theta_{r_{1}} \exp \left[-x_{1}\right]\left(k_{2} \frac{\partial x_{2}}{\partial k_{2}}+1+x_{2}\right)+\left(1-\theta_{r_{1}}\right) \frac{\left(\left(1-\theta_{r_{1}}\right)+\theta_{r_{1}} \exp \left[-x_{1}\right]\right)}{\left(1-\theta_{r_{1}}\right)+\theta_{r_{1}} \exp \left[-x_{1}\right] \exp \left[\lambda_{2} r_{L B, 2}\right]}+\frac{\partial H\left[x_{1}\right]}{d r_{L B, 2}} \frac{d r_{L B, 2}}{d x_{2}} \frac{\partial x_{2}}{\partial k_{2}}}{-H^{\prime}\left[x_{1}\right]}\right)$

Where $\frac{\partial x_{2}}{\partial k_{2}}=\frac{\partial x_{2 \log } / \partial k_{2}}{-\left(-1+\partial x_{2 \log } / \partial x_{2}\right)}<0$ and $\frac{d x_{2}}{d x_{1}}=\frac{\partial x_{2 \log } / \partial x_{1}}{-\left(-1+\partial x_{2 \log } / \partial x_{2}\right)}<0$

$=\frac{\partial x_{2}}{\partial k_{2}}\left(1-\frac{\left(-\theta_{r_{1}} \exp \left[-x_{1}\right] k_{2}-\frac{\partial H\left[x_{1}\right]}{d r_{L B, 2}} \frac{d r_{L B, 2}}{d x_{2}}\right) \frac{d x_{2}}{d x_{1}}}{-H^{\prime}\left[x_{1}\right]}\right)+\frac{d x_{2}}{d x_{1}}\left(\frac{\theta_{r_{1}} \exp \left[-x_{1}\right]\left(1+x_{2}\right)+\left(1-\theta_{r_{1}}\right) \frac{\left(\left(1-\theta_{r_{1}}\right)+\theta_{r_{1}} \exp \left[-x_{1}\right]\right.}{\left(1-\theta_{r_{1}}\right)+\theta_{r_{1}} \exp \left[-x_{1}\right] \exp \left[\lambda_{2} r_{L B, 2}\right]}}{-H^{\prime}\left[x_{1}\right]}\right)<0$

Because $\left(-\theta_{r_{1}} \exp \left[-x_{1}\right] k_{2}-\frac{\partial H\left[x_{1}\right]}{d r_{L B, 2}} \frac{d r_{L B, 2}}{d x_{2}}\right) \frac{d x_{2}}{d x_{1}}<-H^{\prime}\left[x_{1}\right]$

It follows that also $\frac{d r_{L B, 2}}{d L_{2}}<0$ and $\frac{d r_{L B, 2}}{d k_{2}}>0$.

Proof of $\frac{d x_{2}}{d R_{2}}>0, \frac{d x_{2}}{d p_{2}}<0, \frac{d r_{L B, 2}}{d R_{2}}>0$ and $\frac{d r_{L B, 2}}{d p_{2}}<0$

$\frac{d x_{2}}{d R_{2}}=\frac{\partial x_{2}}{\partial R_{2}}+\frac{d x_{2}}{d x_{1}} \frac{\left(\theta_{r_{1}} \exp \left[-x_{1}\right] k_{2}+\frac{\partial H\left[x_{1}\right]}{d r_{L B, 2}} \frac{d r_{L B, 2}}{d x_{2}}\right) \frac{\partial x_{2}}{\partial R_{2}}+\frac{\partial H\left[x_{1}\right]}{d r_{L B, 2}} \frac{d r_{L B, 2}}{d R_{2}}}{-H^{\prime}\left[x_{1}\right]}$

where $\frac{\partial x_{2}}{\partial R_{2}}-\frac{\partial x_{2 \log } / \partial R_{2}}{-\left(-1+\partial x_{2 \log } / \partial x_{2}\right)}>0$ and $\frac{d x_{2}}{d x_{1}}=\frac{\partial x_{2 \log } / \partial x_{1}}{-\left(-1+\partial x_{2 \log } / \partial x_{2}\right)}<0$ 
$=\frac{\partial x_{2}}{\partial R_{2}}\left(1-\frac{\left(-\theta_{r_{1}} \exp \left[-x_{1}\right] k_{2}-\frac{\partial H\left[x_{1}\right]}{d r_{L B, 2}} \frac{d r_{L B, 2}}{d x_{2}}\right) \frac{d x_{2}}{d x_{1}}}{-H^{\prime}\left[x_{1}\right]}\right)+\frac{d x_{2}}{d x_{1}} \frac{\frac{\partial H\left[x_{1}\right]}{d r_{L B, 2}} \frac{d r_{L B, 2}}{d R_{2}}}{-H^{\prime}\left[x_{1}\right]}>0$ because, again

$\left(-\theta_{r_{1}} \exp \left[-x_{1}\right] k_{2}-\frac{\partial H\left[x_{1}\right]}{d r_{L B, 2}} \frac{d r_{L B, 2}}{d x_{2}}\right) \frac{d x_{2}}{d x_{1}}<-H^{\prime}\left[x_{1}\right]$

$\frac{d x_{2}}{d p_{2}}<0$ is shown in a similar way.

$\frac{d r_{L B, 2}}{d R_{2}}=\frac{\partial r_{L B, 2}}{\partial R_{2}}+\frac{d r_{L B, 2}}{d x_{2}} \frac{d x_{2}}{d R_{2}}=\frac{\partial r_{L B, 2}}{\partial R_{2}}+\frac{d r_{L B, 2}}{d x_{2}}\left(\frac{\partial x_{2}}{\partial R_{2}}+\frac{d x_{2}}{d x_{1}} \frac{d x_{1}}{d R_{2}}\right)$

$=\frac{\partial r_{L B, 2}}{\partial R_{2}}+\frac{d r_{L B, 2}}{d x_{2}} \frac{\partial x_{2}}{\partial R_{2}}+\frac{d r_{L B, 2}}{d x_{2}} \frac{d x_{2}}{d x_{1}} \frac{d x_{1}}{d R_{2}}$ where $\frac{d r_{L B, 2}}{d x_{2}} \frac{d x_{2}}{d x_{1}} \frac{d x_{1}}{d R_{2}}>0$ and

$\frac{\partial r_{L B, 2}}{\partial R_{2}}+\frac{d r_{L B, 2}}{d x_{2}} \frac{\partial x_{2}}{\partial R_{2}}=$

$\frac{\partial r_{L B, 2}}{\partial R_{2}}\left(1-\frac{\exp \left[x_{2}\right]\left(\exp \left[r_{L B, 2} \lambda_{2}\right] \theta_{r_{1}}+\exp \left[x_{1}\right]\left(1-\theta_{r_{1}}\right)\left(1+r_{L B, 2} \lambda_{2}\right)\right)}{\left(\left(-1+\exp \left[x_{2}\right]\right) \exp \left[x_{1}\right]\left(1-\theta_{r_{1}}\right)+\exp \left[r_{L B, 2} \lambda_{2}\right] \theta_{r_{1}}\left(-1+\mathrm{e}^{x 2}\right)+\exp \left[x_{2}\right]\left(\exp \left[r_{L B, 2} \lambda_{2}\right] \theta_{r_{1}}+\exp \left[x_{1}\right]\left(1-\theta_{r_{1}}\right)\left(1+r_{L B, 2} \lambda_{2}\right)\right)\right)}\right)>0$

Proof of $\frac{d x_{2}}{d \lambda_{2}}>0$ and $\frac{d r_{L B, 2}}{d \lambda_{2}}<0$.

$\frac{d x_{2}}{d \lambda_{2}}=\frac{\partial x_{2}}{\partial \lambda_{2}}+\frac{d x_{2}}{d x_{1}} \frac{\theta_{r_{1}} \exp \left[-x_{1}\right] k_{2} \frac{\partial x_{2}}{\partial \lambda_{2}}+\frac{\partial H\left[x_{1}\right]}{\partial \lambda_{2}}+\frac{\partial H\left[x_{1}\right]}{\partial r_{L B, 2}} \frac{d r_{L B, 2}}{d x_{2}} \frac{\partial x_{2}}{\partial \lambda_{2}}}{-H^{\prime}\left[x_{1}\right]}$

Where $\frac{\partial x_{2}}{\partial \lambda_{2}}=\frac{\partial x_{2 \log } / \partial \lambda_{2}}{-\left(-1+\partial x_{2 \log } / \partial x_{2}\right)}>0$ and $\frac{d x_{2}}{d x_{1}} \frac{\partial x_{2 \log } / \partial x_{1}}{-\left(-1+\partial x_{2 \log } / \partial x_{2}\right)}<0$

$=\frac{\partial x_{2}}{\partial \lambda_{2}}\left(1-\frac{\left(-\theta_{r_{1}} \exp \left[-x_{1}\right] k_{2}-\frac{\partial H\left[x_{1}\right]}{\partial r_{L B, 2}} \frac{d r_{L B, 2}}{d x_{2}}\right) \frac{d x_{2}}{d x_{1}}}{-H^{\prime}\left[x_{1}\right]}\right)+\frac{d x_{2}}{d x_{1}} \frac{\frac{\partial H\left[x_{1}\right]}{\partial \lambda_{2}}}{-H^{\prime}\left[x_{1}\right]}>0$

where it's easy to see that $\frac{\partial H\left[x_{1}\right]}{\partial \lambda_{2}}<0$. It also follows that $\frac{d r_{L B, 2}}{d \lambda_{2}}<0$. 


\section{Proofs of Proposition 5.}

The proof for the within period changes in $A R_{1}$ and $m p_{1}$ found in the upper left quadrant of Table 3 for $\frac{d A R_{1}}{d L_{1}}<0, \frac{d m p_{1}}{d L_{1}}>0, \frac{d A R_{1}}{d k_{1}}>0$, and $\frac{d m p_{1}}{d k_{1}}<0$ is similar to the proof found in Proposition 2

(Table 1) where, as in Corollary $1, \frac{d A R_{1}}{d x_{1}}<0$ and $\frac{d m p_{1}}{d x_{1}}>0$.

Numerical proof of $\frac{d A R_{1}}{d R_{1}}<0, \frac{d m p_{1}}{d R_{1}}<0, \frac{d A R_{1}}{d p_{1}}>0$ and $\frac{d m p_{1}}{d p_{1}}>0$

We prove this result using numerical methods.

In a Mathematica notebook, we start with a set of parameters that produces an interior solution obtained by using the "FindRoot" function, which solves for the simultaneous values of $x_{1}$ and $x_{2}$, This initial vector equals

$\left\{p_{1} \rightarrow 1, R_{1} \rightarrow a, \theta \rightarrow 0.4, R_{2} \rightarrow 8, L_{2} \rightarrow 10, p_{2} \rightarrow 1.5, L_{1} \rightarrow 8, k_{1} \rightarrow 2, k_{2} \rightarrow 1, \lambda_{1} \rightarrow 0.1, \lambda_{2} \rightarrow 0.1, r_{1} \rightarrow 12, r_{2} \rightarrow 12\right\}$

We then vary the parameter of interest. In this case it is $R_{l}$, which is varied from 4 to 11 .

We also check randomly using other initial vectors and could find no instance where the direction of change differed than what is shown below. We used a similar technique for other numerical analyses in Proposition 5, as noted below. This Mathematica notebook is available upon request.

Note that the following graphs are examples of the analysis performed
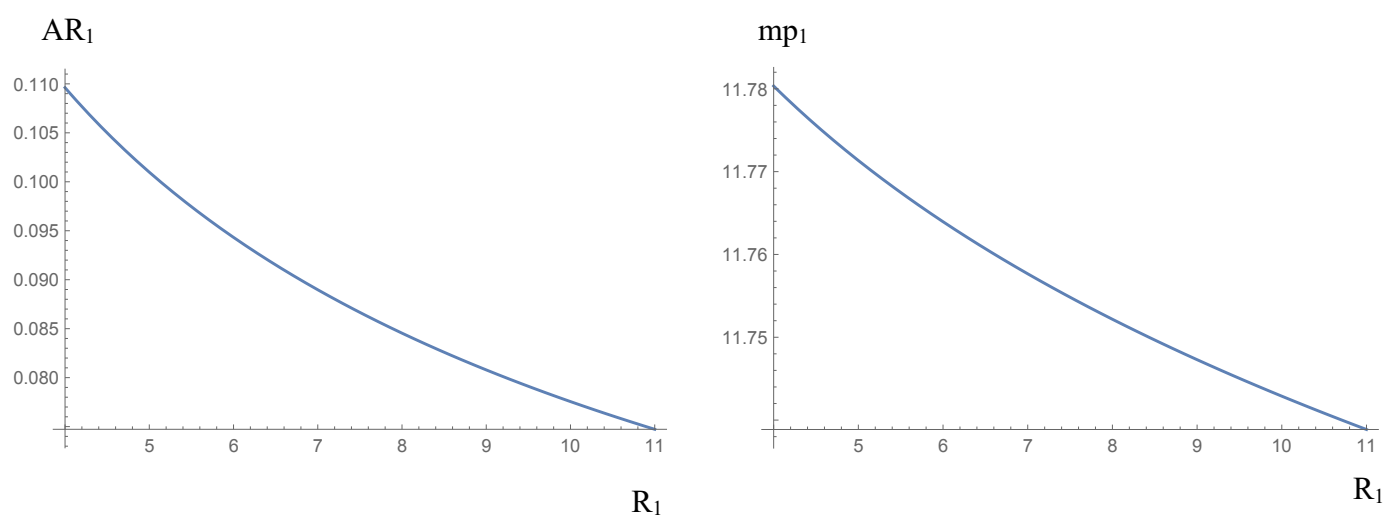

In a similar fashion, we show that $\frac{d A R_{1}}{d p_{1}}>0$ and $\frac{d m p_{1}}{d p_{1}}>0$

Numerical proof of $\frac{d A R_{1}}{d \lambda_{1}}>0$ and $\frac{d m p_{1}}{d \lambda_{1}}<0$ (or $\frac{d A R_{1}}{d\left(1 / \lambda_{1}\right)}<0$ and $\left.\frac{d m p_{1}}{d\left(1 / \lambda_{1}\right)}>0\right)$. 
We prove this result using numerical methods.

Note that the following graphs are examples of the analysis performed.

In this case, $1 / \lambda_{1}$ is varied from 10 to 30 .
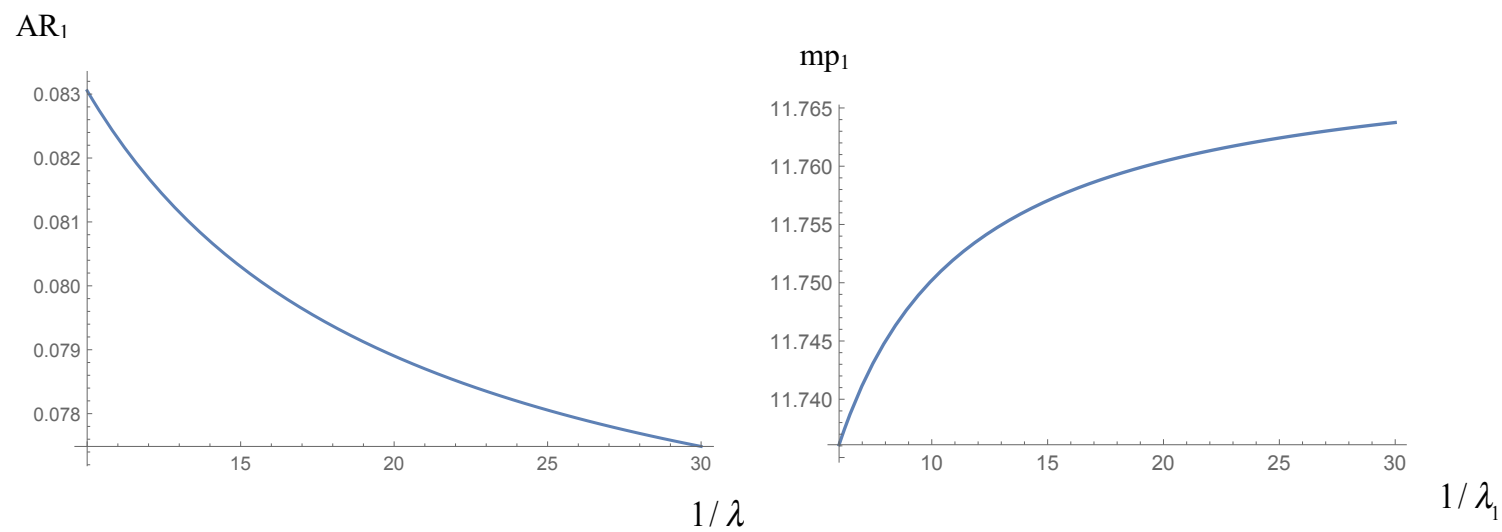

Lower left quadrant of Table 3.

Proof of $\frac{d A R_{1}}{d L_{2}}<0, \frac{d m p_{1}}{d L_{2}}>0, \frac{d A R_{1}}{d k_{2}}<0$, and $\frac{d m p_{1}}{d k_{2}}>0$

$\frac{d A R_{1}}{d L_{2}}=\frac{d A R_{1}}{d x_{1}} \frac{d x_{1}}{d L_{2}}<0$ and $\frac{d m p_{1}}{d L_{2}}=\frac{d m p_{1}}{d x_{1}} \frac{d x_{1}}{d L_{2}}>0$ based on Corollary 1 and $\frac{d x_{1}}{d L_{2}}>0$, as shown in

Proposition 4.

Similarly, for $\frac{d A R_{1}}{d k_{2}}<0$, and $\frac{d m p_{1}}{d k_{2}}>0$.

Proof of $\frac{d A R_{1}}{d R_{2}}<0, \frac{d m p_{1}}{d R_{2}}>0, \frac{d A R_{1}}{d p_{2}}>0$, and $\frac{d m p_{1}}{d p_{2}}<0$

$\frac{d m p_{1}}{d R_{2}}=\frac{d m p_{1}}{d x_{1}} \frac{d x_{1}}{d R_{2}}>0, \frac{d A R_{1}}{d R_{2}}=\frac{d A R_{1}}{d x_{1}} \frac{d x_{1}}{d R_{2}}<0, \frac{d m p_{1}}{d p_{2}}=\frac{d m p_{1}}{d x_{1}} \frac{d x_{1}}{d p_{2}}<0$ and $\frac{d A R_{1}}{d p_{2}}=\frac{d A R_{1}}{d x_{1}} \frac{d x_{1}}{d p_{2}}>0$

In a similar fashion, $\frac{d m p_{1}}{d p_{2}}>0$

Proof of $\frac{d m p_{1}}{d \lambda_{2}}<0$ and $\frac{d A R_{1}}{d \lambda_{2}}>0$ (or equivalently, $\frac{d m p_{1}}{d\left(1 / \lambda_{2}\right)}>0$ and $\frac{d A R_{1}}{d\left(1 / \lambda_{2}\right)}<0$ )

$\frac{d m p_{1}}{d \lambda_{2}}=\frac{d m p_{1}}{d x_{1}} \frac{d x_{1}}{d \lambda_{2}}<0$ and $\frac{d A R_{1}}{d \lambda_{2}}=\frac{d A R_{1}}{d x_{1}} \frac{d x_{1}}{d \lambda_{2}}>0$

\section{Upper right quadrant of Table 3.}


Proof of $\frac{d m p_{2}}{d L_{1}}>0, \frac{d A R_{2}}{d L_{1}}<0, \frac{d m p_{2}}{d k_{1}}<0$ and $\frac{d A R_{2}}{d k_{1}}>0$

$\frac{d m p_{2}}{d L_{1}}=\frac{d m p_{2}}{d x_{1}} \frac{d x_{1}}{d L_{1}}+\frac{d m p_{2}}{d x_{2}} \frac{d x_{2}}{d x_{1}} \frac{d x_{1}}{d L_{1}}=\frac{d x_{1}}{d L_{1}}\left(\frac{d m p_{2}}{d x_{1}}+\frac{d m p_{2}}{d x_{2}} \frac{d x_{2}}{d x_{1}}\right)$

$=-\frac{2 \exp \left[x_{2}+2 r_{L B, 1} \lambda_{1}+2 r_{L B, 2} \lambda_{2}\right] r_{L B, 2} \theta^{2}}{\left(\exp \left[x_{1}+x_{2}\right](1-\theta)+\exp \left[r_{L B, 1} \lambda_{1}+r_{L B, 2} \lambda_{2}\right] \theta\right)^{2}} \frac{d x_{2}}{d x_{1}} \frac{d x_{1}}{d L_{1}}>0$

$\frac{d A R_{2}}{d L_{1}}=\frac{d A R_{2}}{d x_{1}} \frac{d x_{1}}{d L_{1}}+\frac{d A R_{2}}{d x_{2}} \frac{d x_{2}}{d x_{1}} \frac{d x_{1}}{d L_{1}}=\frac{d x_{1}}{d L_{1}}\left(\frac{d A R_{2}}{d x_{1}}+\frac{d A R_{2}}{d x_{2}} \frac{d x_{2}}{d x_{1}}\right)$

$=\frac{\exp \left[r_{L B, 1} \lambda_{1}+r_{L B, 2} \lambda_{2}\right] \theta}{\left(-1+\exp \left[x_{1}\right]\right)\left(\exp \left[x_{1}\right](1-\theta)+\exp \left[r_{L B, 1} \lambda_{1}+r_{L B, 2} \lambda_{2}\right] \theta\right)} \frac{d x_{2}}{d x_{1}} \frac{d x_{1}}{d L_{1}}<0$

The proofs for $\frac{d A R_{2}}{d k_{1}}>0$, and $\frac{d m p_{2}}{d k_{1}}<0$ are similar.

Proof of $\frac{d A R_{2}}{d R_{1}}<0$ and $\frac{d A R_{2}}{d p_{1}}>0$

After substituting for equilibrium strategies, audit risk in period $2 A R_{2}=\frac{k_{2}}{L_{2} r_{L B, 2}}$ where Proposition 4 shows that $\frac{d r_{L B, 2}}{d R_{1}}>0$ and $\frac{d r_{L B, 2}}{d p_{1}}<0$.

Numerical proof of $\frac{d m p_{2}}{d R_{1}}>0$ and $\frac{d m p_{2}}{d p_{1}}<0$

For this we use numerical analysis.

Note that the following graph is an example of the analysis performed.

In this case, $R_{1}$ is varied from 5 to 11 . 


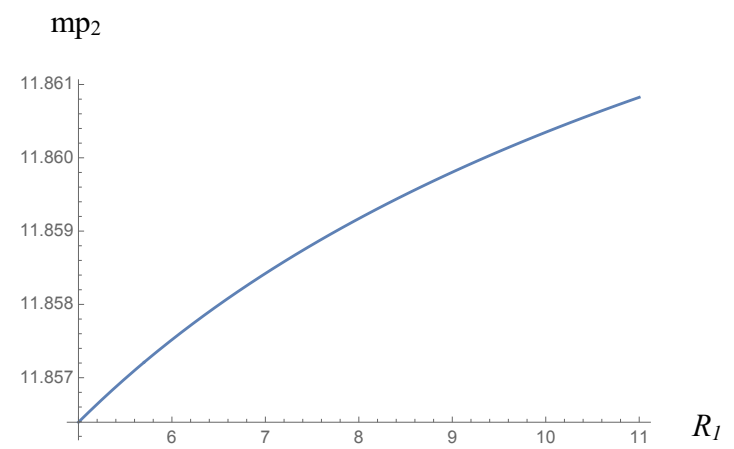

Similarly, we can show that $\frac{d m p_{2}}{d p_{1}}<0$.

Proof of $\frac{d A R_{2}}{d \lambda_{1}}>0 \quad\left(\right.$ or $\left.\frac{d A R_{2}}{d\left(1 / \lambda_{1}\right)}<0\right)$.

Again, we know that $A R_{2}=\frac{k_{2}}{L_{2} r l b_{2}}$ and $\frac{d r l b_{2}}{d \lambda_{1}}<0$ based on Proposition 4.

Numerical proof of $\frac{d m p_{2}}{d \lambda_{1}}<0$ (or $\frac{d m p_{2}}{d\left(1 / \lambda_{1}\right)}>0$ ).

For this we use numerical analysis.

Note that the following graph is an example of the analysis performed.

In this case, $1 / \lambda_{2}$ is varied from 5 to 30 .

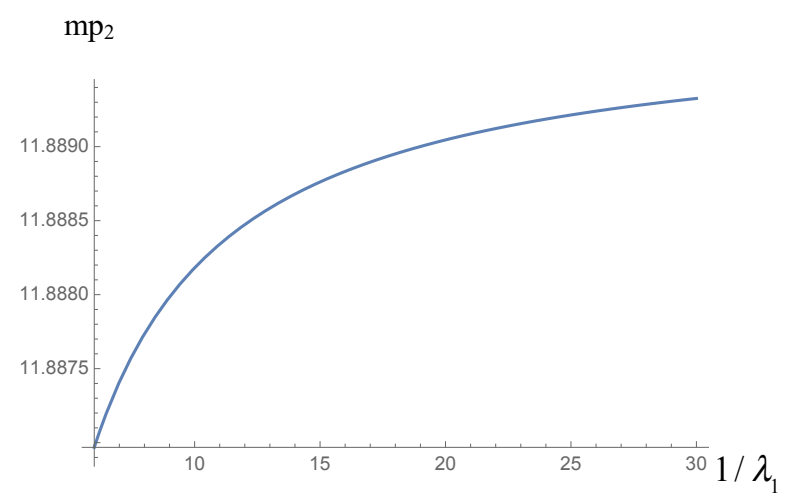

\section{Lower right quadrant of Table 3.}

Proof of $\frac{d m p_{2}}{d L_{2}}>0, \frac{d A R_{2}}{d L_{2}}<0, \frac{d m p_{2}}{d k_{2}}<0$ and $\frac{d A R_{2}}{d k_{2}}>0$

$\frac{d m p_{2}}{d L_{2}}=\frac{d m p_{2}}{d x_{1}} \frac{d x_{1}}{d L_{2}}+\frac{d m p_{2}}{d x_{2}} \frac{d x_{2}}{d x_{1}} \frac{d x_{1}}{d L_{2}}=\frac{d x_{1}}{d L_{2}}\left(\frac{d m p_{2}}{d x_{1}}+\frac{d m p_{2}}{d x_{2}} \frac{d x_{2}}{d x_{1}}\right)$ 
$=-\frac{2 \exp \left[x_{2}+2 r_{L B, 1} \lambda_{1}+2 r_{L B, 2} \lambda_{2}\right] r_{L B, 2} \theta^{2}}{\left(\exp \left[x_{1}+x_{2}\right](1-\theta)+\exp \left[r_{L B, 1} \lambda_{1}+r_{L B, 2} \lambda_{2}\right] \theta\right)^{2}} \frac{d x_{2}}{d x_{1}} \frac{d x_{1}}{d L_{2}}>0$

$\frac{d A R_{2}}{d L_{2}}=\frac{d A R_{2}}{d x_{1}} \frac{d x_{1}}{d L_{2}}+\frac{d A R_{2}}{d x_{2}} \frac{d x_{2}}{d x_{1}} \frac{d x_{1}}{d L_{2}}=\frac{d x_{1}}{d L_{2}}\left(\frac{d A R_{2}}{d x_{1}}+\frac{d A R_{2}}{d x_{2}} \frac{d x_{2}}{d x_{1}}\right)$

$=\frac{\exp \left[r_{L B, 1} \lambda_{1}+r_{L B, 2} \lambda_{2}\right] \theta}{\left(-1+\exp \left[x_{1}\right]\right)\left(\exp \left[x_{1}\right](1-\theta)+\exp \left[r_{L B, 1} \lambda_{1}+r_{L B, 2} \lambda_{2}\right] \theta\right)} \frac{d x_{2}}{d x_{1}} \frac{d x_{1}}{d L_{2}}<0$

The proof for $\frac{d A R_{2}}{d k_{1}}>0$, and $\frac{d m p_{2}}{d k_{1}}<0$ is similar.

Proof of $\frac{d A R_{2}}{d R_{2}}<0$ and $\frac{d A R_{2}}{d p_{2}}>0$.

The above is true based on $A R_{2}=\frac{k_{2}}{L_{2} r_{L B, 2}}$ where Proposition 4 shows that $\frac{d r_{L B, 2}}{d R_{2}}>0$ and $\frac{d r_{L B, 2}}{d p_{2}}<0$.

Numerical proof of $\frac{d m p_{2}}{d R_{2}}<0$ and $\frac{d m p_{2}}{d p_{2}}>0$

For this we use numerical analysis.

In this case, $R_{2}$ is varied from 5 to 11 .

Note that the following graph is an example of the analysis performed.

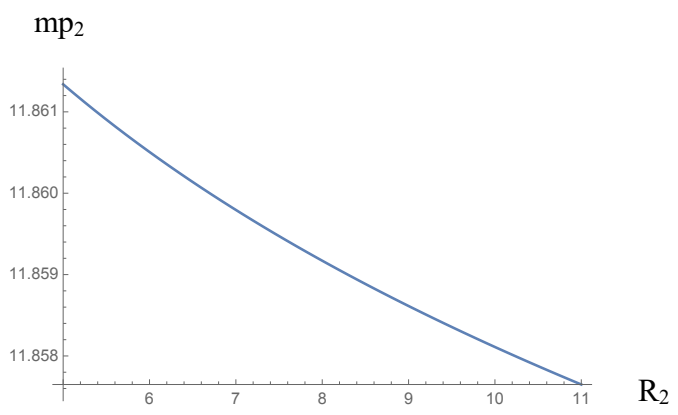

Similarly, for $\frac{d m p_{2}}{d p_{2}}>0$

Proof of $\frac{d A R_{2}}{d \lambda_{2}}>0$ and (or $\frac{d A R_{2}}{d\left(1 / \lambda_{2}\right)}<0$ ). 
The above is true based on $A R_{2}=\frac{k_{2}}{L_{2} r_{L B, 2}}$ where Proposition 4 shows that $\frac{d r_{L B, 2}}{d \lambda_{2}}<0$.

Proof of $\frac{d m p_{2}}{d \lambda_{2}}<0$ (or $\left.\frac{d m p_{2}}{d\left(1 / \lambda_{2}\right)}>0\right)$.

$$
\frac{d m p_{2}}{d \lambda_{2}}=\frac{d m p_{2}}{d x_{1}} \frac{d x_{1}}{d \lambda_{2}}+\frac{d m p_{2}}{d x_{2}} \frac{d x_{2}}{d x_{1}} \frac{d x_{1}}{d \lambda_{2}}+\frac{d m p_{2}}{d \lambda_{2}}=\frac{d x_{1}}{d \lambda_{2}}\left(\frac{d m p_{2}}{d x_{1}}+\frac{d m p_{2}}{d x_{2}} \frac{d x_{2}}{d x_{1}}\right)+\frac{d m p_{2}}{d \lambda_{2}}
$$

$=-\frac{2 \exp \left[x_{2}+2 r_{L B, 1} \lambda_{1}+2 r_{L B, 2} \lambda_{2}\right] r_{L B, 2} \theta^{2}}{\left(\exp \left[x_{1}+x_{2}\right](1-\theta)+\exp r_{L B,}\left[r_{L B, 1} \lambda_{1}+r_{L B, 2} \lambda_{2}\right] \theta\right)^{2}} \frac{d x_{2}}{d x_{1}} \frac{d x_{1}}{d \lambda_{2}}-\frac{\exp \left[x_{1}+x_{2}+r_{L B, 1} \lambda_{1}+r_{L B, 2} \lambda_{2}\right] r_{L B, 2}{ }^{2}(1-\theta) \theta}{\left(\exp \left[x_{1}+x_{2}\right](1-\theta)+\exp \left[r_{L B, 1} \lambda_{1}+r_{L B, 2} \lambda_{2}\right] \theta\right)^{2}}<0$

where $\frac{d x_{2}}{d x_{1}}<0, \frac{d x_{1}}{d \lambda_{2}}<0$. 


\section{References}

Bryan, D., C. Liu, S. Tiras, and Z. Zhuang. 2013. Optimal versus suboptimal choices of accounting expertise on audit committees and earnings quality. Review of Accounting Studies 18: 11231158.

Burgstahler, D. and I. Dichev. 1997. Earnings management to avoid earnings decreases and losses. Journal of Accounting and Economics 24: 344-401.

Casella, G. and R. L. Berger. 1990. Statistical Inference. California: Duxbury Press.

Caskey, J., V. Nagar, and P. Petacchi. 2010. Reporting bias with an audit committee. The Accounting Review 85 (2): 447-481.

Cohen, D. and P. Zarowin. 2007. Earnings Management over the Business Cycle. Working paper. New York University.

Dechow, P., W. Ge, and C. Schrand. 2010. Understanding earnings quality: A review of the proxies, their determinants and their consequences. Journal of Accounting and Economics 50 (2-3): 344-401.

DeFond, M., R. Hann, R., and X. Hu. 2005. Does the market value financial expertise on audit committees of boards of directors? Journal of Accounting Research, 43 (2): 153-193.

DeFond, M. and J. Zhang. 2014. A review of archival auditing research. Journal of Accounting and Economics 58 (2-3): 275-326.

Degeorge, F., J. Patel, and R. Zeckhauser. 1999. Earnings management to exceed thresholds. Journal of Business 72 (1): 1-33.

Erard, B., and J. S. Feinstein. 1994. Honesty and evasion in the tax compliance game. RAND Journal of Economics 25 (Spring): 1-19.

Fischer, P. and R. Verrecchia. 2000. Reporting bias. The Accounting Review 75 (2): 229-245.

Kothari S.P. 2001. Capital markets research in accounting. Journal of Accounting and Economics, $31,105-231$.

Newman, D.P., E.R. Patterson, and J.R. Smith. 2001. The influence of potentially fraudulent reports on audit risk assessment and planning. The Accounting Review 76 (1): 59-80.

Paulo, E. and R. H. G. Mota. 2015. Business cycles and earnings management strategies: a study in Brazilian public firms. Revista Contabilidade \& Finanças. 30 (80): 216-233.

Patterson, E.R. and J.R. Smith. 2007. The effects of Sarbanes-Oxley on auditing and internal control strength. The Accounting Review 82(2): 427-455.

Patterson, E. R., J. R. Smith, and S. L. Tiras. 2019a. The Effects of Auditor Tenure on Fraud and Its Detection. The Accounting Review. 94 (4): forthcoming. 
Patterson, E. R., J. R. Smith, and S. L. Tiras. 2019b. "The Interrelation between Audit Quality and Managerial Reporting Choices and Its effects on Financial Reporting Quality." Contemporary Accounting Research. 36 (1) 861-1882.

Skinner, D. J., and R. G. Sloan. 2002. Earnings surprises, growth expectations, and stock returns or don't let an earnings torpedo sink your portfolio. Review of Accounting Studies 7: 289-312.

Wang, H., Q. Li and Y. Chen. 2015. Earnings management, business cycle, and product market competition. China Journal of Accounting Studies. 3 (2). 136-157.

Wilkinson, J. 2015. Does fraud follow economic cycles? The Strategic CFO. https://strategiccfo.com/does-fraud-follow-economic-cycles. 